\title{
La contaminación lumínica: implicaciones urbanísticas, demaniales y de eficiencia energética
}

\author{
Isabel González Ríos \\ Profesora Titular de Derecho Administrativo de la Universidad de Málaga
}

\begin{abstract}
Sumario: I. INTRODUCCIÓN. - II. DISTRIBUCIÓN DE COMPETENCIAS. EL PAPEL DE LOS ENTES LOCALES. - III. NORMATIVA REGULADORA. 1. Regulación estatal. 2.Regulación Autonómica. 3. Regulación local.-IV. EL CONCEPTO DE CONTAMINACIÓN LUMÍNICA. OBJETO Y FINALIDADES DE SU REGULACIÓN. 1. Concepto. 2. Objeto y finalidades de su regulación. - V.-TÉCNICAS DE INTERVENCIÓN CONTRA LA CONTAMINACIÓN LUMÍNICA PREVISTAS EN LA NORMATIVA AUTONÓMICA. 1. Técnicas o instrumentos de prevención. A) La zonificación del territorio. B) Prohibiciones, limitaciones y exigencias técnicas con relación a instalaciones, aparatos y horario nocturno de iluminación. C) El control de la contaminación lumínica mediante el otorgamiento de autorizaciones. D) Control de la contaminación lumínica a través de la contratación administrativa. 2. Técnicas de control. A) La obligación de adaptación de los alumbrados exteriores. B) La inspección y el régimen sancionador. 3. Medidas económicas.-VI. LA CONTAMINACIÓN LUMÍNICA: IMPLICACIONES URBANÍSTICAS Y DEMANIALES. 1. El alumbrado público y otras redes de iluminación. 2. La utilización del dominio público local con instalaciones de iluminación. - VII. LA EFICIENCIA ENERGÉTICA COMO ELEMENTO CLAVE EN LA LUCHA CONTRA LA CONTAMINACIÓN LUMÍNICA. 1. Normativa reguladora del sector eléctrico. 2. La eficiencia energética.-VIII. CONCLUSIONES.
\end{abstract}

\section{INTRODUCCIÓN}

La contaminación lumínica, entendiendo por tal la contaminación producida por una iluminación excesiva e innecesaria, que comenzó siendo objeto de atención de los astrofísicos, viene cobrando una especial relevancia para la Doctrina y para el legislador.

La pluralidad de bienes jurídicos, incluso derechos, que se tratan de proteger cuando se lucha contra dicha contaminación avala la necesidad de dar respuesta normativa al problema. La protección de la visión del cielo nocturno, como elemento integrante, del paisaje, el derecho a una vivienda digna y adecuada libre de inmisiones contaminantes ${ }^{1}$, la protección de los hábitats nocturnos frente a la incidencia perjudicial de dicho tipo de contaminación y, por último, y no por ello menos importante, la necesidad de dar cumplimiento a los objetivos marcados por la Unión Europea y a nivel interno de ahorro y eficiencia

\footnotetext{
1 Derecho reconocido en el art. 47 de la CE y expresamente previsto en el art. 4.a) de la Ley 8/07, de 28 de mayo del Suelo, que se refiere al derecho de todo ciudadano a disfrutar de una vivienda digna y adecuada «libre de ruido y otras inmisiones contaminantes de cualquier tipo que superen los límites máximos admitidos por la legislación aplicable y en un medio ambiente y un paisaje adecuado».
} 
energética, son elementos claves para que la contaminación lumínica sea objeto de un tratamiento normativo, doctrinal y jurisprudencial exhaustivo.

En este marco, este estudio pretende contribuir al conocimiento de este fenómeno contaminante y, sobre todo, a la realización de propuestas para prevenir, controlar y luchar contra el mismo.

$\mathrm{Al}$ respecto se analizan los distintos títulos competenciales que inciden en la materia, partiendo del más directamente afectado, cual es la protección del medio ambiente, para a continuación analizar toda la normativa relativa a la misma y desglosar su concepto. En la medida en que la regulación legislativa de la protección contra la contaminación lumínica sólo se ha realizado en varias CCAA, se analizan los instrumentos de prevención, control y lucha contra la contaminación lumínica previstos en dichas legislaciones.

Sin embargo, la prevención y lucha contra dicha contaminación no podía limitarse al estudio de la legislación autonómica específica en esa materia, porque sólo cinco CCAA cuentan con ella, Cataluña, Islas Baleares, Navarra, Cantabria y Andalucía, y porque el fenómeno, a falta de una regulación básica estatal completa, exige del análisis de otras legislaciones que inciden en el tema, principalmente, la urbanística, la de bienes demaniales y la del sector eléctrico y sobre eficiencia energética. Ello sin olvidar la abundante normativa sectorial que contiene referencias a la iluminación de distintos tipos de bienes demaniales como las costas, los puertos o las carreteras.

\section{DISTRIBUCIÓN DE COMPETENCIAS. EL PAPEL DE LOS ENTES LOCALES}

La Contaminación Lumínica viene a ser una nueva forma de contaminación, que se ha visto potenciada en los países más desarrollados y frente a la cual desde hace unas décadas se vienen produciendo reacciones. Así pues, puede integrarse en el título competencial genérico sobre protección del medio ambiente.

La distribución de competencias en dicha materia ha sido ampliamente tratada por la Doctrina y por la Jurisprudencia del Tribunal Constitucional ${ }^{2}$. Se

\footnotetext{
2 Sirvan como muestra de la evolución de la doctrina constitucional en la materia las Sentencias 64/82, 69/82, 170/89, 149/91 y 102/95.

La distribución de competencias en materia de medio ambiente ha sido tratada, entre otros, por: MARTíN Mateo, R.: Tratado de Derecho Ambiental.Vol.I. Ed. Trivium. Madrid. 1991. LoZAno Cutanda, B.: Derecho Ambiental Administrativo. Ed. Dykinson. Madrid. 2006. AlenZa García, José F.: Manual de Derecho Ambiental. Universidad Pública de Navarra (2002, págs. 73 y ss.). VERA JURADO, D.J.: «La evaluación de impacto ambiental y las competencias ejecutivas en materia de medio ambiente: un análisis de la jurisprudencia del Tribunal Constitucional», RAP n. ${ }^{\circ} 148$ (1999). Alonso GARCíA, R., LOZANO CuTANDA, B., PlAZA MARTín, C.: «El medio ambiente ante el Tribunal Constitucional: problemas competenciales y ultraeficacia
} 
trata de una materia de competencia compartida, donde al Estado le corresponde dictar la legislación básica sobre protección del medio ambiente y a las CCAA la legislación de desarrollo y el establecimiento de normas adicionales de protección (art. 149.1.23 y 148.1.9 CE) ${ }^{3}$. También el municipio ostenta competencias en la materia en virtud del art. 25.2.f) y 1) LBRL que le atribuye competencias para la protección del medio ambiente y sobre alumbrado público, en los términos que le reconozca la legislación estatal y autonómica.

Más adelante analizaremos las competencias que las legislaciones autonómicas reguladoras de la contaminación lumínica han atribuido a los municipios.

Si bien este es el título competencial habilitador para regular la contaminación lumínica, lo cierto es que otros títulos competenciales inciden en la materia desde perspectivas distintas.

En primer lugar, nos referimos a una contaminación producida por una fuente de energía, de ahí el término «lumínica». En materia energética al Estado le corresponde la regulación de la normativa básica y la autorización de las instalaciones eléctricas cuando su aprovechamiento afecte a otra CCAA o el transporte de energía salga de su ámbito territorial, así como, la iluminación de costas y señales marítimas (art. 149.1.25,22, 20 de la CE, respectivamente).

Las CCAA pueden desarrollar la legislación básica del Estado en materia energética ${ }^{4}$. Además, los municipios ejercerán en todo caso competencias sobre alumbrado público, en los términos que se determine en la correspondiente legislación estatal y autonómica.

En segundo lugar, la contaminación lumínica se relaciona, y quizá ahí se encuentre erróneamente el surgimiento de la misma, con el mantenimiento de la seguridad pública. Se tiende a pensar que cuanto más iluminadas estén las zonas urbanas más seguras serán, lo que técnicamente está demostrado que no es cierto. La iluminación en exceso no sirve de nada, tampoco para la seguridad pública.

\footnotetext{
protectora». RAP n. ${ }^{\circ} 148$ (1999). BELTRÁN AGUIRRE, J.L: «La distribución de competencias entre el Estado y las Comunidades Autónomas en materia de medio-ambiente». RVAP, n. 41 (1995). DELGADO PIQUERAS, F.: «Régimen jurídico del derecho constitucional al medio ambiente», Revista Española de Derecho Constitucional, n. 38 (1993). LóPEZ MENUdo, F.: «Planteamiento Constitucional del Medio Ambiente. Distribución de competencias Estado-Comunidades Autónomas», en la obra Protección Administrativa del Medio Ambiente, Cuadernos de Derecho Judicial. CGPJ, Madrid, 1994; «Concepto de medio ambiente y reparto competencial», en el libro colectivo, coordinado por VERA JURADO, D.J: Derecho ambiental de Andalucía. Ed. Tecnos. Madrid. 2005. Agudo GonZÁleZ, J.: «Las competencias de la Comunidad Europea en materia medioambiental y su incidencia en el ejercicio de las competencias en el ámbito interno». RDU y MA n. ${ }^{\circ} 172$ (1999, págs. 125 y ss.).

3 Vid, STC 166/102.

4 V.gr. Art. 49 de la Ley Orgánica 2/07, de Reforma del Estatuto de Autonomía de Andalucía; art. 31.1 de la Ley Orgánica 1/07, de 28 de mayo, de Reforma del Estatuto de Autonomía de las Islas Baleares; art. 133 de la Ley Orgánica 6/06, de 19 de julio, de Reforma del Estatuto de Autonomía de Cataluña.
} 
La competencia en materia de seguridad pública corresponde al Estado sin perjuicio de la posibilidad de creación de policías autonómicas por las CCAA en la forma que se establezca en sus respectivos Estatutos en el marco de una Ley Orgánica. En el ámbito municipal la legislación estatal debe reconocer competencias en materia de seguridad en lugares públicos (art. 25.2.a) LBRL). La Ley Orgánica 1/92, de 21 de febrero, de Protección de la Seguridad Ciudadana se refiere a las competencias municipales vinculadas a espectáculos públi$\cos ^{5}$, actividades recreativas y actividades molestas, insalubres, nocivas y peligrosas, de acuerdo con la normativa por la que se rijan 6 .

En tercer lugar, para que se produzca la susodicha contaminación debe existir la correspondiente infraestructura de iluminación que la provoque, pública o privada, respecto de la cual pueden intervenir tanto las CCAA como los municipios desde su competencia en materia de ordenación del territorio y urbanismo (art. 148.1.3 CE).

Otros títulos competenciales como el establecimiento de las bases y coordinación general de la sanidad (art. 149.1.16 CE), que es competencia exclusiva del Estado, inciden en el tema desde el momento en que la contaminación lumínica puede afectar a la salud humana, que puede verse afectada por la intrusión de luz nocturna en los hogares, impidiendo el debido descanso; o la competencia estatal de fomento y coordinación general de la investigación científica y técnica (art. 149.1.15 CE), materia en la que todas las CCAA han asumido competencias ${ }^{7}$. La importancia de este título competencial se refleja en que las primeras críticas a la contaminación lumínica proceden del campo de la investigación científica, concretamente de las Asociaciones de Astrónomos que necesitan ver las estrellas y demás astros para su estudio. La contaminación lumínica está reduciendo y, en algunos casos, eliminando dicho objeto de estudio.

Así pues, distintos títulos competenciales inciden en la materia de la contaminación lumínica, pero es sin duda la protección del medio ambiente el título predominante por cuanto estamos hablando de un tipo de contaminación que afecta a la calidad del medio ambiente.

Por otra parte, la Comunidad Europea puede adoptar medidas contra la contaminación lumínica desde su competencia en materia de medio ambiente (Título XIX del Tratado de la Unión Europea). Los objetivos que se proclaman respecto de la política de la Unión Europea en el ámbito del medio ambiente encajan perfectamente en la lucha contra este tipo de contaminación. Así, «la conservación, la protección y la mejora de la calidad del medio ambiente; la protección de la salud de las personas; el fomento de medidas a escala internacional destinadas a hacer frente a los problemas regionales o mundiales, del medio ambiente» (art. 174 del Tratado de la Unión Europea).

\footnotetext{
5 Real Decreto 2816/82, de 27 de agosto, Reglamento de Policía de Espectáculos.

6 Art. 2.2 de la Ley Orgánica 1/92, de 21 de febrero, de Protección de la Seguridad Ciudadana.

7 Vg. Art. 13.29 Estatuto de Autonomía de Andalucía.
} 
Además, la Unión Europea puede intervenir en materia de investigación y desarrollo tecnológico (Título XVIII del Tratado de la Unión Europea). Está así habilitada para adoptar medidas de control de la contaminación lumínica para favorecer la investigación Astronómica en el ámbito de la Comunidad Europea.

La pluralidad de títulos competenciales que inciden en la materia de la contaminación lumínica y el predominio del referido a la protección del medio ambiente nos lleva a percatarnos de la posibilidad de luchar contra este fenómeno contaminante desde una regulación integral del mismo, o bien mediante medidas puntuales a adoptar en determinadas políticas sectoriales, como la eficiencia energética o el urbanismo principalmente.

\section{NORMATIVA REGULADORA}

\section{Regulación estatal}

La primera ley estatal promulgada con el objeto de controlar la contaminación lumínica fue la llamada «Ley del cielo», Ley 31/1988, de 31 de octubre, sobre Protección de la Calidad Astronómica de los Observatorios del Instituto de Astrofísica de Canarias, desarrollada por Real Decreto 243/92, de 13 de marzo.

Esta ley tiene un ámbito territorial de aplicación y un objeto restringido. Así, sólo resulta aplicable a la CCAA de Canarias más concretamente, a la isla de Tenerife y de la Palma donde se sitúan los Observatorios del Instituto de Astrofísica de Canarias.

$\mathrm{Su}$ objeto es establecer limitaciones a aquellas actividades que puedan ser fuente de contaminación lumínica en sentido estricto, o sea, que sean degradantes para la calidad atmosférica de los citados observatorios ${ }^{8}$. Así, establece una limitación elemental como es que la iluminación de exteriores ${ }^{9}$, salvo las necesarias para garantizar la navegación aérea, evite la emisión de luz por encima del horizonte.

Para conseguir este objetivo se establecen prescripciones técnicas al respecto de la construcción, instalación y tipo de lámparas de las luminarias para alumbrado vial. Así se prevé que la luminaria no proyecte luz hacia arriba o lados, sólo hacia abajo, que se coloquen sin ninguna inclinación, que como re-

8 Art. 1 de la Ley 31/88, de 31 de octubre.

9 O sea, «todo tipo de alumbrado realizado con instalaciones estables o esporádicas, en recintos abiertos para su utilización nocturna» (art. 4 Real Decreto 243/92, de 13 de marzo). Por ejemplo, alumbrado vial, anuncios luminosos, alumbrado exterior de viviendas particulares, alumbrado ornamental y de parques, etcétera. 
gla general se usen lámparas de vapor de sodio a baja presión, nunca lámparas de vapor de mercurio o halogenuros metálicos; además, dichas luminarias deben ir previstas de un mecanismo que permita reducir el flujo luminoso a un $1 / 3$ del normal a partir de las 12 de la noche. A partir de esa hora deberán quedar apagados el alumbrado de edificios públicos, monumentos y jardines, instalaciones de recreo y deportivas o anuncios luminosos.

De gran importancia para llevar a cabo las prescripciones contenidas en la Ley del Cielo y en su Reglamento de desarrollo resulta la previsión de un régimen sancionador, que se remite a la normativa específica según el tipo de actividad que produzca la contaminación lumínica, así como, la previsión de que los gastos que ocasione a las islas afectadas la adaptación de la iluminación pública exterior previamente existente y el sobrecoste de las nuevas instalaciones será subvencionado por el Estado. De lo que se deduce que la adaptación del alumbrado exterior privado: anuncios luminosos, escaparates de zonas comerciales, alumbrado exterior de particulares, etc., deberá ser sufragado por los mismos.

Recientemente en la Ley de Calidad del Aire y Protección de la Atmósfera ${ }^{10}$ se ha incluido la definición y algunas previsiones sobre este específico tipo de contaminación. Al respecto contiene un mandato a las Administraciones públicas para que, en el ámbito de sus competencias, promuevan la prevención y reducción de la contaminación lumínica con la finalidad de conseguir objetivos tales como: el uso eficiente del alumbrado exterior, preservar las condiciones naturales de las horas nocturnas en beneficio de los ecosistemas y para garantizar la visión del cielo nocturno y reducir la intrusión lumínica en zonas distintas a las que se pretende iluminar, principalmente respecto a entornos naturales e interior de los edificios ${ }^{11}$.

Pero esta Ley sólo se refiere a la contaminación lumínica como fenómeno que incide en la protección de la atmósfera, pero no realiza una regulación íntegra de la misma. Dicha Ley se declara aplicable a una serie de contaminantes, recogidos en el Anexo I, entre los que no se pueden incluir las emisiones de luz a la atmósfera. De ahí que la contaminación lumínica merezca una mención especial en cuanto a su definición y a la previsión de que las Administraciones públicas adopten las medidas necesarias para su prevención y reducción.

A la vista de esta escasa regulación básica sobre este específico tipo de contaminación queda clara que su regulación va a quedar en manos de las CCAA y, en su defecto, de los entes locales. Se desaprovecha así la ocasión para realizar una mínima regulación de carácter básico sobre la contaminación lumínica, necesaria en cuanto en muchas zonas, pensemos las zonas costeras, este tipo de contaminación excede el ámbito municipal y en, el algunos casos, el autonómi-

10 Ley 34/07, de 15 de noviembre, de Calidad del Aire y Protección de la Atmósfera.

11 Disposición Adicional Cuarta de la Ley 34/07, de 15 de noviembre, de Calidad del Aire y Protección de la Atmósfera. 
co, y por cuanto la lucha contra la contaminación lumínica debe formar parte de la política de eficiencia energética marcada por el Gobierno, como más adelante analizaremos.

No obstante, la reciente aprobación del Reglamento estatal de Eficiencia Energética en Instalaciones de Alumbrado Exterior, supone un paso adelante en la aprobación de normativa de carácter básico que incide de forma directa en la protección contra la contaminación lumínica.

En dicho Reglamento se establecen las condiciones técnicas de diseño, ejecución y mantenimiento que deben reunir las instalaciones de alumbrado exterior, con la doble finalidad de mejorar la eficiencia y el ahorro energético, así como la disminución de las emisiones de gases de efecto invernadero, y limitar el resplandor luminoso nocturno o contaminación luminosa, reduciendo la luz intrusa o molesta.

\section{Regulación autonómica}

La contaminación lumínica resulta ser una de las formas de contaminación que más escasa atención ha merecido para el legislador autonómico. Prueba de ello es que en el momento de escribir estas líneas sólo cuatro CCAA han regulado de forma específica la materia, siendo en ello pionera Cataluña ${ }^{12}$. Otras, como Andalucía, regulan los aspectos más destacados de este tipo de contaminación realizando una regulación integral sobre calidad ambiental ${ }^{13}$.

Así, siguiendo la línea de la Ley del Cielo, se vienen aprobando leyes reguladoras del fenómeno de la contaminación lumínica por diversas CCAA. La CCAA de Cataluña inicia el camino en la regulación de este tipo de contaminación con la aprobación de la Ley de Ordenación Ambiental del Alumbrado para la Protección del Medio Nocturno ${ }^{14}$. A la misma le han seguido la Ley de Protección del Medio Nocturno de las Islas Baleares ${ }^{15}$, la Ley de Ordenación del Alumbrado para la Protección del Medio Nocturno de la Comunidad Foral

\footnotetext{
12 JORDANO FRAGA, Jesús: «Medio ambiente veinte años después del Estatuto». RAAP n. ${ }^{\circ}$ Extraordinario 2/2003 (pág. 372 y ss.).

13 Ley 7/07, de 9 de julio, de Gestión Integrada de la Calidad Ambiental, de Andalucía.

14 Ley 6/01, de 31 de mayo, de Ordenación Ambiental del Alumbrado para la Protección del Medio Nocturno. Esta Ley ha sido desarrollada por el Decreto 82/05, de 3 de mayo, por el que se aprueba el Reglamento en dicha materia, el cual ha sido declarado nulo de pleno derecho por la Sentencia de 7 de diciembre de 2007 del Tribunal Superior de Justicia de Cataluña (Pte.Ana Rubira Moreno, fj.3. ${ }^{\circ}$ ), debido a que en su aprobación se ha eludido un trámite esencial del procedimiento cual es el de información pública y audiencia a los ciudadanos. El Tribunal manifiesta que dicho trámite resulta ineludible para «garantizar el acierto y la oportunidad de la disposición, a través de la participación ciudadana tal como preconiza el art. 105 del Texto Legal Constitucional».
}

15 Ley 3/05, de 20 de abril, de Protección del medio nocturno de las Islas Baleares. 
Navarra ${ }^{16}$, la Ley de Prevención de la Contaminación Lumínica de Cantabria ${ }^{17}$ o Ley Andaluza de Gestión Integrada de la Calidad Ambiental. La peculiaridad de esta última Ley está en la regulación integrada de la calidad ambiental, en la que se incluye la calidad del medio ambiente atmosférico, refiriéndose a los diferentes tipos de contaminación que pueden afectarla: la atmosférica, la lumínica y la acústica.

El resto de CCAA se abstienen de la regulación de un fenómeno novedoso. Ello no impide que algunas CCAA, principalmente aquellas que cuentan con una regulación específica en la materia, se refieran a la necesidad de prevenir la contaminación lumínica cuando regulan la ordenación del territorio y el urbanismo, la planificación de los recursos naturales, el turismo, los puertos, etcétera.

En este sentido son significativas la Ley de la Generalitat Valenciana de Ordenación del Territorio y Protección del Paisaje que al referirse a la mejora de los entornos urbanos, como garantía de calidad de vida de los ciudadanos, se refiere entre las actuaciones que deben adoptar los poderes públicos a la «implantación de medidas y técnicas destinadas a lograr una mayor calidad del ambiente urbano mediante la disminución de la contaminación acústica y vibraciones, la reducción de la contaminación lumínica, y de cualquier emisión o elemento que perturbe la calidad de la atmósfera» ${ }^{18}$. Esta CCAA también se refiere a la necesidad de conseguir la eficiencia energética en la iluminación de exteriores de los campos de Golf evitando la contaminación lumínica ${ }^{19}$.

Por su parte, la CCAA de Canarias incide sectorialmente sobre el tema al regular las directrices de ordenación general y del turismo, estableciendo que el Gobierno de Canarias debe cuidar la calidad lumínica del archipiélago, estableciendo niveles adecuados para el mantenimiento de la actividad de observación astrofísica en óptimas condiciones, el ahorro y aprovechamiento de la energía y el respeto a la vida silvestre, además se establece cómo se debe llevar a cabo el control lumínico ${ }^{20}$.

16 Ley Foral 10/05, de 9 de noviembre, de Ordenación del Alumbrado para la Protección del Medio Nocturno de la Comunidad Foral Navarra. Esta Ley ha sido desarrollada por el Decreto 199/07, de 17 de septiembre, que aprueba el Reglamento de dicha Ley.

17 Ley 6/06, de 9 de junio, de Prevención de la Contaminación Lumínica de Cantabria.

18 Ley 4/04, de 30 de junio, de Ordenación del Territorio y Protección del Paisaje, de la Generalitat Valenciana (art. 5.2.d), y su Reglamento de desarrollo aprobado por Decreto 67/06, de 19 de mayo de Ordenación y Gestión Territorial y Urbanística (art. 8 y 52). El Reglamento de desarrollo de esta Ley establece la necesidad de realizar reservas de suelo para instalaciones y aparatos de vigilancia y control de la contaminación lumínica, acústica y atmosférica. Estas reservas de suelo se deben realizar por el planeamiento urbanístico y tendrán la consideración de elementos de la red primaria de dotaciones pública.

19 Art. 37.3 de la Ley 9/06, de 5 de diciembre, reguladora de los Campos de Golf de la Generalitat Valenciana.

20 Ley 19/03, de 14 de abril, por la que se aprueban las Directrices de Ordenación General y las Directrices de Ordenación del Turismo de Canarias. 
La Ley de Evaluación Ambiental de la Comunidad Autónoma de Madrid ${ }^{21}$ establece que el estudio de la incidencia ambiental de los documentos de planeamiento evaluará y propondrá medidas y acciones tendentes a la protección del medio nocturno, minimizando la contaminación lumínica de los nuevos desarrollos urbanísticos propuestos.

También la ordenación del litoral ${ }^{22}$, la planificación de los puertos ${ }^{23}$ o de los recursos naturales ${ }^{24}$ ha llevado a algunas CCAA a referirse a la necesidad de que la respectiva planificación prevenga y minorice la contaminación lumínica en la visión del cielo.

\section{Regulación local}

Las competencias que la legislación de régimen local atribuye a los municipios en materia de protección del medio ambiente, de alumbrado público y de ordenación y disciplina urbanística, muestran el importante papel que los municipios pueden y deben jugar en la materia, sobre todo, a la vista de la regulación estatal y del escaso interés mostrado por las CCAA en su regulación.

Además las CCAA que han regulado la contaminación lumínica atribuyen importantes competencias a los municipios sobre la zonificación del territorio atendiendo a su vulnerabilidad ante aquel tipo de contaminación; el régimen propio de alumbrado por acontecimientos singulares, feriales, deportivos, culturales, etc; en cuanto a ejercicio de la potestad sancionadora o determinación de la franja horaria en que los alumbrados exteriores permanecerán apagados.

Han sido variadas las iniciativas de Ordenanzas locales aprobadas por municipios con el objeto de controlar y prevenir este tipo de contaminación

\footnotetext{
21 Ley 2/02, de 19 de junio, de Evaluación Ambiental de la Comunidad Autónoma de Madrid.

22 Ley 2/04, de 27 de septiembre, por la que se aprueba el Plan de Ordenación del Litoral de Cantabria (art. 16).

23 Al respecto el Decreto 206/01, de 24 de julio, que aprueba el Reglamento de Policía Portuaria de Cataluña, recoge la obligación de los titulares y usuarios de locales comerciales de cumplir la normativa sobre prevención de la contaminación lumínica. A su vez, el Decreto 44/07, de 20 de febrero, por el que se aprueba el Plan de Puertos de Cataluña, establece que las instalaciones portuarias tienen que adoptar las medidas ambientales relativas a la implantación del sistema de gestión ambiental, de eficiencia energética y de reducción de la contaminación lumínica (art. 10).

24 Vid, Decreto 57/04, de 17 de febrero, que aprueba el Plan de Ordenación de los Recursos Naturales y el Plan Rector de uso y gestión del Parque Natural de Sierra Mágica; el Decreto 259/04, de 19 de noviembre, del Consell de la Generalitat, por el que se aprueba el Plan Rector de uso y gestión del Parque Natural de L`Albufera; el Decreto 58/05, de 11 de marzo, del Consell de la Generalitat, por el que se aprueba el Plan de Ordenación de los Recursos Naturales de la Serra Gelada y su zona litoral. En estos Reglamentos se establece la necesidad de reducir la contaminación lumínica por las actividades que se desarrollen dentro de los citados Parques.
} 
y a la vez conseguir el ahorro energético ${ }^{25}$. Pero más destacado si cabe es la regulación de una Propuesta de Modelo de Ordenanza municipal de alumbrado exterior para la protección del medio ambiente mediante la mejora de la eficiencia energética elaborada en 2002 por un grupo de trabajo formado por el Consejo Español de Iluminación y el Instituto para la Diversificación y Ahorro de la Energía (IDEA) ${ }^{26}$. Y ello, en primer lugar, porque ya en el año 2002 la lucha contra la contaminación lumínica se percibe como una materia de competencia local, tengamos en cuenta que en esa fecha sólo Cataluña contaba con normativa sobre contaminación lumínica; y, en segundo lugar, porque la prevención de la contaminación lumínica se vincula a la necesidad de conseguir la eficiencia energética, óptica asociada a la misma, como se deduce de la naturaleza jurídica del organismo que aprueba la Propuesta de Ordenanza ${ }^{27}$.

\section{EL CONCEPTO DE CONTAMINACIÓN LUMÍNICA. OBJETO Y FINALIDADES DE SU REGULACIÓN}

\section{Concepto $^{28}$}

Frente a otros tipos de contaminación como la atmosférica, la del agua, la radioactiva, o más recientemente, la acústica, la contaminación lumínica resulta ser un fenómeno menos conocido.

No obstante, desde un punto de vista científico hace tiempo que su concepto se encuentra claramente establecido ${ }^{29}$. Así, se entiende por contaminación lumínica toda luz que se emite por encima de la horizontal de las luminarias instaladas en el alumbrado exterior y que produce un halo o resplandor luminoso al ponerse en contacto con las partículas de polvo o agua que el aire contiene en suspensión.

\footnotetext{
25 Vid los ejemplos de Ordenanzas municipales en la materia citados por CASADO CASADO, L. «Las Administraciones públicas ante la contaminación lumínica. Análisis del modelo de prevención y control instaurado en Cataluña. REDA n. ${ }^{\circ} 134$ (2007; pág. 330).

26 Propuesta de Modelo de Ordenanza municipal de alumbrado exterior para la protección del medio ambiente mediante la mejora de la eficiencia energética, Instituto para la Diversificación y Ahorro de la Energía (IDEA). Madrid, 2002 (http://www.idae.es/index.php/mod.publicaciones/mem.buscar/relmenu).

27 El IDEA, se constituye como una Entidad Pública Empresarial adscrita al Ministerio de Industria, Comercio y Turismo.

28 Sobre el concepto de contaminación lumínica vid, entre otros: CALVO CHARRO, M.: «La contaminación lumínica. La protección del cielo oscuro», en su libro Escritos de Derecho Ambiental. Tirant Lo Blanch, Valencia. (2003, pág. 24). CASADO CASADO, L.: «El papel de los municipios en la prevención, ordenación y control de la contaminación lumínica», en REALA n. 304 (2007, págs. 140 y ss.).

29 La importancia del tema se refleja en la cantidad de páginas Webs que se dedican a la información sobre la problemática que la contaminación lumínica conlleva, entre las que destacan las impulsadas por los Observatorios Astrofísicos (vg www.astrogea.org/celfos/contaminacionluminica.htm).
} 
De esta definición se deduce que sólo se considera contaminante la emisión de luz por encima de la horizontal de las luminarias. Es la iluminación en exceso y proyectada hacia el cielo ${ }^{30}$.

Este es un concepto estricto de contaminación lumínica que se vincula con la dificultad o imposibilidad de observar el cielo nocturno, que implica un considerable derroche de energía y, consecuentemente, una mayor emisión de gases contaminantes a la atmósfera.

A dicha definición podemos unir un concepto amplio que considera también contaminación lumínica aquellos flujos luminosos que por su intensidad y dirección iluminan zonas que no resultan necesarias para realizar las actividades previstas en los lugares donde se han colocado los puntos luminosos ${ }^{31}$. Con esta definición añadimos tres consecuencias más a la contaminación lumínica, la intromisión en la vida privada de las personas por una incorrecta e inadecuada iluminación de las fachadas de las viviendas ${ }^{32}$, el deslumbramiento luminoso, que perjudica a la seguridad de las personas, principalmente a la seguridad vial, y la incidencia perjudicial en determinados habitats naturales ${ }^{33}$.

La Jurisprudencia contiene todavía pronunciamientos escasos sobre la contaminación lumínica. No obstante, algunas sentencias de los Tribunales Superiores de Justicia recogen a veces el concepto vinculándolo a la contaminación lumínica producida por los vehículos a motor, a la que posteriormente nos refe-

\footnotetext{
30 Calvo Charro, M.a : «El derecho a ver las estrellas. Análisis de la contaminación lumínica desde una perspectiva jurídica». RDU y MA m. ${ }^{\circ} .187$ (2001, pág. 131). «La contaminación lumínica. La protección del cielo oscuro», en su libro Escritos de Derecho Ambiental. Ed.Tirant Lo Blanch. Valencia (2003, pág. 24). «Contaminación lumínica» en la obra colectiva Diccionario de Derecho Ambiental dirigida por ALONSO GARCÍA, E. y LOZANO CUTANDA, B. Ed. Iustel (2006, págs. 382-393).
}

31 ASIAIN GARCÍA, Ricard y FERNÁNDEZ BARBA, David: «Contaminación lumínica». Anuario 1995-1999. Fin de Siglo. Ed. Tibidabo Ediciones. JAuME FERnÁNDEZ, Carles: «La contaminación lumínica en nuestros municipios. Reflexiones en torno a los instrumentos jurídicos para combatirla desdelos Ayuntamientos»(artículo electrónico, puede consultarse en www.dialnet.unirioja.es/).

32 No hemos de olvidar que como desarrollo del art. 47 de la Constitución Española, la Ley 8/07, de 28 de mayo, del Suelo recoge el derecho de todo ciudadano a disfrutar de una vivienda digna, adecuada y accesible, concebida con arreglo al principio de diseño para todas las personas, haciendo especial mención a que esa vivienda constituya su domicilio libre de ruido u otras inmisiones contaminantes de cualquier tipo que superen los límites máximos admitidos por la legislación aplicable (art. 4.a).

El art. 8 del Convenio para la Protección de los Derechos Humanos y de las Libertades Públicas, de 4 de noviembre de 1950 recoge el derecho de toda persona al respeto a su vida privada y familiar y de su domicilio. Vid las STEDU de 9 de diciembre de 1994 (caso López Ossa) y la de 2 de noviembre de 2006 (caso Giacomelli).

Sobre los derechos ciudadanos que pueden verse afectados por la contaminación lumínica, vid, ENTRENA RUIZ, D.: «La prevención contra la contaminación lumínica mediante la ordenación del territorio y urbanismo», en Ecosostenible, (julio 2005, pág. 21).

33 El principio de desarrollo territorial y urbano sostenible que recoge la Ley 8/07, de 28 de mayo, del Suelo (art. 2) exige adoptar medidas eficaces de conservación y mejora de la naturaleza, la flora y la fauna y de la protección del patrimonio cultural y del paisaje. No cabe duda que la prevención de la contaminación lumínica incide en dicho objetivo. 
riremos, o por el alumbrado público en cuanto a la intrusión que provoca en viviendas privadas. En relación a esto último, la Sentencia de 19 de diciembre de 2006 del Tribunal Superior de Justicia de la Comunidad Valenciana (Pte. María D. Iruela Jiménez, fj.3..$^{\circ}$ ) anula un acuerdo del Ayuntamiento de El Campello que disponía la renovación y potenciación del alumbrado público en una calle por la contaminación lumínica, entendida como intromisión de luz en una vivienda, que producía la colocación de las luminarias. El Tribunal tras recoger el concepto doctrinal de contaminación lumínica considera que la modificación de las instalaciones de iluminación, que en un principio estaban proyectadas con farolas de un brazo situadas en la fachada del edificio en cuestión, por la instalación de farolas en la acera delante de la vivienda del recurrente provoca aquel tipo de contaminación. Argumenta el Tribunal que la protección frente a este tipo de contaminación se fundamenta en el principio de proporcionalidad que debe presidir el ejercicio de toda potestad administrativa de intervención y que exige la utilización del medio más eficaz y adecuado y que resulte menos gravoso y restrictivo de los intereses particulares. Además, el derecho de toda persona a disfrutar de un medio ambiente adecuado para el desarrollo de la persona (art. $45 \mathrm{CE}$ ) y el derecho constitucional a la intimidad familiar y a la inviolabilidad del domicilio, avalan la necesidad de proteger a los ciudadanos que sufran atentados medioambientales por contaminación lumínica.

Se observa en tal sentido la utilización de un concepto amplio de este tipo de contaminación.

Cabe preguntarse si existe una definición legal de contaminación lumínica. Si partimos de un análisis cronológico, la norma pionera en España para controlar la contaminación lumínica, la Ley sobre Protección de la Calidad Astronómica de los Observatorios del Instituto de Astrofísica de Canarias ${ }^{34}$, también llamada «Ley del cielo», si bien no define la contaminación lumínica, comparte el concepto estricto que hemos expuesto, al tener como objeto preservar la calidad astronómica de los observatorios del citado Instituto de Astrofísica ${ }^{35}$.

A dicha Ley le siguió la regulación autonómica sobre contaminación lumínica realizada por Comunidades Autónomas como Cataluña, Baleares, Navarra, Cantabria y, más recientemente, Andalucía. Las legislaciones autonómicas de Cataluña, Cantabria y Andalucía realizan una conceptuación expresa de la contaminación lumínica partiendo del concepto amplio antes expuesto ${ }^{36}$. Las

\footnotetext{
34 Ley 31/88, de 31 de octubre, sobre Protección de la Calidad Astronómica de los Observatorios del Instituto de Astrofísica de Canarias.

35 Así, se deduce del art. 2 de la Ley del Cielo y del art. 6 del Real Decreto 243/92, de 13 de marzo, que desarrolla la citada ley, que establecen que las iluminaciones de exteriores, excluidas las precisas para garantizar la navegación aérea, deberán evitar la emisión de luz por encima del horizonte, añadiendo que deben realizarse de forma que produzcan la mínima perturbación de las observaciones astronómicas.

36 El art. 4.1.a) de la Ley 6/01, de 31 de mayo, de Ordenación Ambiental del Alumbrado para la Protección del Medio Nocturno, de Cataluña; el art. 2.a) de la Ley 6/06, de 9 de junio, de Prevención de la Contamina-
} 
mismas centran el concepto en dos aspectos, el primero, la emisión nocturna de flujo luminoso procedente de fuentes artificiales, el segundo, la dirección e intensidad innecesaria de dichos flujos en relación a las actividades a realizar en la zona alumbrada. En consecuencia, la contaminación se produce por la emisión de una fuente de energía luminosa en exceso.

Otras CCAA no han definido el fenómeno pero, puesto que su finalidad no es sólo preservar la visión del cielo nocturno, se puede deducir que aceptan un concepto amplio de contaminación lumínica, tal es el caso de la normativa de las Islas Baleares o de la Comunidad Foral Navarra ${ }^{37}$.

Más recientemente el legislador viene refiriéndose a la contaminación lumínica como un tipo más de contaminación que afecta a la calidad y protección del medio ambiente atmosférico. Así, nos encontramos ya con una escueta regulación básica estatal en la materia en la Ley de Calidad del Aire y Protección de la Atmósfera que define la contaminación lumínica como el resplandor luminoso nocturno o brillo producido por la difusión y reflexión de la luz en las partículas y gases en suspensión en la atmósfera que altera las condiciones de las horas nocturnas y dificultan las observaciones astronómicas ${ }^{38}$.

Este concepto se ciñe más al concepto estricto de contaminación lumínica que a la visión más amplia que de este fenómeno hemos de tener a fin de atender a la protección del máximo tipo de bienes o intereses que se ven afectados con la misma. Ello resulta lógico en la medida en que se trata de una Ley de protección de la calidad del aire y de la atmósfera. No obstante, la prevención de la contaminación lumínica debe tener como objetivos no sólo la visión nocturna del cielo, como objetivo principal, sino también, la protección de la salud humana, evitando la intrusión lumínica, o de la flora y la fauna cuando estas puedan verse afectadas.

Lo que parece claro a la luz de la Ley Estatal de Calidad del Aire y Protección de la Atmósfera y de la Ley Andaluza de Gestión Integrada de la Contaminación Ambiental es que el concepto de contaminación lumínica se diferencia del de contaminación atmosférica o del aire, con el que, sin embargo, se encuentra íntimamente relacionado. Esta relación se manifiesta, en primer lugar, porque ambos tipos de contaminación afectan a la calidad del aire y, en segundo lugar, porque la contaminación lumínica también genera contaminación atmosférica. Podría decirse que una de las formas de contaminación atmosférica es la contaminación lumínica, por las emisiones de gases que se producen como con-

ción Lumínica, de la Comunidad Autónoma de Cantabria. Y más recientemente, el art. 50.4 de la Ley 7/07, de 9 de julio, de Gestión Integrada de la Calidad Ambiental, de Andalucía.

37 Art. 1 y 2 de la Ley 3/05, de 20 de abril, de Protección del Medio Nocturno de las Islas Baleares; art. 1 y 2 de la Ley Foral 10/05, de 9 de noviembre, de Ordenación del Alumbrado para la Protección del Medio Nocturno.

38 Art. 3.f) de la Ley 34/07, de 15 de noviembre, de Calidad del Aire y Protección de la Atmósfera. 
secuencia de la producción de la energía necesaria para realizar la iluminación nocturna de exteriores. En consecuencia con la aplicación de las técnicas de prevención y control de la contaminación lumínica se contribuye también a luchar contra la contaminación atmosférica.

La protección contra la contaminación lumínica debe partir del concepto amplio analizado, a fin de poder garantizar la protección de bienes jurídicos diversos como la visión nocturna del cielo ${ }^{39}$, especialmente importante para las observaciones astrofísicas, y de otros bienes como la salud de las personas y la protección de su intimidad frente a la intrusión luminosa nocturna que perturba el descanso, o de los habitats naturales, que pueden verse alterados, así como, la necesidad de garantizar el ahorro y eficiencia energética.

\section{Objeto y finalidades de su regulación}

Partiendo del concepto de contaminación lumínica analizado hemos de identificar el objeto de regulación con las instalaciones y aparatos de alumbrado susceptibles de producir dicho tipo de contaminación. No obstante, toda la normativa autonómica que se refiere a la contaminación lumínica excluye de su aplicación determinadas instalaciones, que aún siendo susceptibles de provocar contaminación lumínica se consideran que no deben sujetarse al régimen de limitaciones y prohibiciones que dicha normativa recoge. Nos referimos a las instalaciones de iluminación que garantizan la seguridad del tráfico (aéreo, terrestre o marítimo), las de carácter militar, las relacionadas con actividades o instalaciones de las Fuerzas y Cuerpos de Seguridad del Estado, protección civil, extinción de incendios o los vehículos a motor ${ }^{40}$. En general cualquier tipo de iluminación que esté prevista para garantizar la seguridad de los ciudadanos o del tráfico.

39 Entre los bienes objeto de protección ambiental debe incluirse la visión del cielo nocturno, como elemento propio del paisaje. Sobre la protección del paisaje como bien de protección ambiental, entre otros: LOZANO CutAnda, B.: Derecho Ambiental..., op, cit. FABEIRo Mosquera, A.: «La protección del paisaje, su creciente importancia en el ámbito internacional y la dispersión de instrumentos jurídicos para su protección integral en el derecho español», REDA n. ${ }^{\circ} 131$ (2006, págs. 524 y ss.).

40 Los Tribunales Superiores de Justicia empiezan a utilizar el concepto de contaminación lumínica en relación a la producida por los vehículos a motor, respecto de los cuales se predica también la contaminación acústica. En tal sentido, la Sentencia de 1 de junio de 2007 del Tribunal Superior de Justicia de Madrid (Pte. Francisco J. Sancho Cuesta; fj..$^{\circ}$ ) o la de 14 de septiembre de 2007 del Tribunal Superior de Justicia de la Comunidad Valenciana (Pte. Lorenzo Cotino Hueso; fj.8), donde se alude a la contaminación acústica y lumínica que va a afectar a una vivienda como consecuencia de la mayor proximidad de una carretera a una vivienda tras la expropiación realizada. Esa contaminación lumínica y acústica se utilizan como argumento para fundamentar la necesidad de aumentar el justiprecio expropiatorio por la depreciación sufrida en los terrenos no expropiados.

En consecuencia, si bien queda claro que los vehículos a motor pueden generar contaminación lumínica lo cierto es que la misma no se sujeta a las limitaciones y prohibiciones recogidas en las legislaciones autonómicas en la materia. 
Con relación a dicha exclusión cabe mencionar, como después se dirá, que la misma no debe ser total. Parece más oportuno que la normativa sobre protección contra la contaminación lumínica se remita a las legislaciones sectoriales obligando a que en las mismas también se establezcan medidas de prevención contra dicho tipo de contaminación, sin que ello merme las condiciones de seguridad ciudadana o del tráfico que sus específicos alumbrados tienden a conseguir. Buena muestra de esta práctica la dan aquellas normas dictadas por algunas CCAA en temas sectoriales como la regulación de los puertos, del turismo, de los recursos naturales, de la ordenación del litoral, etc, que incluyen la prevención contra la contaminación lumínica entre sus objetivos, como ya hemos analizado.

Las finalidades que se pretenden conseguir en la prevención y control contra este tipo de contaminación son la eficiencia energética, evitar las intrusiones de luz en las viviendas, garantizar la visión del cielo nocturno, permitiendo el desarrollo de la investigación astrofísica y evitar perjuicios a los ecosistemas naturales que puedan verse afectados. Si bien las primeras reivindicaciones en la lucha contra este tipo de contaminación pretenden garantizar la investigación astrofísica, hoy en día la consecución del ahorro y de la eficiencia energética debe erigirse en objetivo predominante.

\section{TÉCNICAS DE INTERVENCIÓN CONTRA LA CONTAMINACIÓN LUMÍNICA PREVISTAS EN LA NORMATIVA AUTONÓMICA}

\section{Técnicas o instrumentos de prevención}

De la normativa sobre contaminación lumínica autonómica se deduce que las Administraciones públicas competentes deben realizar una intervención preventiva y de control para evitar que se produzca la contaminación lumínica. Dicha intervención debe acompañarse de medidas económicas, puesto que el evitar la contaminación lumínica requiere de una intervención sobre el alumbrado nocturno ya existente, lo que implica la necesidad de realizar importantes desembolsos de dinero.

El análisis de dicha intervención administrativa y de los instrumentos de los que se vale la Administración para llevar a cabo aquella se va a realizar en función de la regulación que sobre contaminación lumínica han realizado las CCAA de Cataluña, Cantabria, Baleares, Navarra y Andalucía. Así, entre dichos instrumentos se encuentran: la zonificación del territorio en función de su vulnerabilidad a este tipo de contaminación, las prohibiciones, limitaciones y exigencias técnicas con relación a las instalaciones, aparatos y horario nocturno de iluminación, el otorgamiento de autorizaciones y las exigencias para la contratación administrativa. 


\section{A) La zonificación del territorio}

Todas las legislaciones autonómicas que regulan la contaminación lumínica parten del establecimiento de un instrumento de ordenación específico de la misma como es la zonificación del territorio en función de su vulnerabilidad a aquel tipo de contaminación según el tipo de uso del suelo. Esta zonificación debe distinguir cuatro tipos de áreas o zonas lumínicas ${ }^{41}$ :

- La E1: es la zona donde se admite un brillo mínimo, o sea, zonas en las que se debe mantener un mayor nivel de oscuridad. Aquí se incluyen, por una parte, los terrenos considerados espacios naturales protegidos 0 incluidos en ámbitos sujetos a una protección especial, y por otra, los espacios destinados a la observación astronómica.

- La E2: la integran áreas donde sólo se admite un brillo reducido.

Al respecto de esta zona lumínica la Ley de Gestión Integrada de la Calidad Ambiental incluye los terrenos clasificados como suelo no urbanizable o urbanizable, no incluidos en el área E1.

- La E3: áreas en las que se admite un brillo medio.

Sólo la Ley de Gestión Integrada de la Calidad Ambiental establece una relación detallada de los terrenos que deben incluirse en esta zona E3, refiriéndose a las zonas residenciales, zonas industriales, zonas dotacionales con utilización en horario nocturno y el sistema general de espacios libres. También la legislación navarra establece que esta zona se integrará normalmente por suelos residenciales urbanos.

- La E4: la forman ámbitos territoriales que admiten un brillo alto. La integran, como ha especificado la Ley de Gestión Integrada de la Calidad Ambiental las zonas incluidas en el casco urbano y aquellas en las que se desarrollen actividades de carácter comercial, turístico y recreativo en horario nocturno.

Las legislaciones de las CCAA de Cataluña, Navarra, Islas Baleares y Cantabria incluyen junto a estas zonas los llamados «puntos de referencia», que son los puntos próximo a una zona E1, para cada uno de los cuales hay que establecer una regulación específica según la zona en la que se encuen-

\footnotetext{
41 Art. 5 de la Ley 6/01, de 31 de mayo, de Ordenación Ambiental del Alumbrado para la Protección del Medio Nocturno de Cataluña; art. 5 de la Ley 3/05, de 20 de abril, de Protección del Medio Nocturno de las Isles Balears; art. 6 de la Ley Foral Navarra 10/05, de 9 de noviembre, de Ordenación del Alumbrado para la Protección del Medio Nocturno y arts. 2 a 9 del Reglamento de desarrollo de 2007; art. 7 de la Ley 6/06, de 9 de julio, de Prevención de la Contaminación Lumínica, de Cantabria; art. 63 de la Ley 7/07, de 9 de julio, de Gestión Integrada de la Calidad Ambiental, de Andalucía.
} 
tren, siendo la distancia al punto de referencia lo que permitirá fijar la iluminación en la zona.

El trasfondo de esta regulación de los puntos de referencia parece ser que junto a las zonas más oscuras, las E1, no exista una iluminación excesiva como puede ocurrir si de forma colindante se determina una zona E3 o E4. Sin embargo, el objetivo pretendido puede conseguirse mejor con la medida adoptada por la Ley de Gestión Integrada de la Calidad Ambiental de Andalucía que prevé que junto a un área E1 sólo podrá establecerse la clasificación E2.

¿Pero a quién corresponde realizar dichas zonificaciones? ${ }^{42}$.

De la normativa autonómica en la materia se deduce que los niveles de protección que se derivan de la zonificación en E1, E2, E3 y E4 deben ser respetados como niveles mínimos de protección contra la contaminación lumínica por los municipios. Ahora bien, la correspondiente zonificación del territorio la realizarán los municipios, bien opcionalmente ${ }^{43}$, como en el caso de las CCAA de Cataluña, las Islas Baleares y Cantabria, o bien, tienen que realizarla de forma obligatoria tal como establecen las correspondientes legislaciones de la comunidad Foral Navarra o de Andalucía. Más concretamente, Andalucía ha establecido que la determinación de las zonas correspondientes al área lumínica E1 la realizará la Consejería competente, mientras que el resto de zonas lumínicas o, incluso, una zonificación propia que respete los niveles mínimos de protección, será una potestad atribuida a los municipios.

No obstante, algunas legislaciones autonómicas han previsto la posibilidad de que los municipios al realizar la zonificación no respeten aquellos niveles mínimos de protección si concurren causas justificadas o en los términos que se establezca reglamentariamente ${ }^{44}$. Esta posibilidad se prohibe expresamente por la legislación de la CCAA de Cantabria, y así se deduce también de la normativa autonómica andaluza.

Dicha previsión resulta criticable desde el momento en que las competencias locales deben ejercerse en esta materia dentro de un marco más amplio establecido por la normativa autonómica, o incluso estatal, porque en caso contrario se corre el riesgo de que los municipios traten de buscar esas «causas justificadas» para no respetar los niveles mínimos de protección contra la contaminación lumínica, con lo que a su vez estarían actuando en contra de las políticas de eficiencia energética.

\footnotetext{
42 Sobre la intervención municipal en la zonificación, vid. CASADO CASADO, L.: «El papel de los municipios...»,op, cit. (págs. 164 y ss.).

43 En este caso resulta claro que la zonificación del territorio debe realizarla la CCAA, al recogerse como una opción, el que la realicen los municipios.

44 Tal es el caso de la CCAA de Cataluña, la Foral Navarra y las Islas Baleares.
} 


\section{B) Prohibiciones, limitaciones y exigencias técnicas en relación a instalaciones, aparatos y horario nocturno de iluminación}

\section{a) Limitaciones y Prohibiciones de iluminación}

La normativa autonómica que venimos analizando establece limitaciones respecto del flujo luminoso que se puede emitir en cada una de las zonas en que se clasifique el territorio teniendo en cuenta el tipo de alumbrado: exterior viario, peatonal, ornamental, industrial, comercial, deportivo y recreativo, de seguridad de edificios, etc.

Junto a dicha limitación, la legislación autonómica Foral Navarra, de las Islas Baleares y de Cantabria recomiendan la utilización de pavimentos con un grado de luminosidad lo más elevado posible y que por sus propiedades reflectantes resulten adecuados para la instalación de alumbrado público. Se trata de una mera recomendación que deja a la discrecionalidad de los Ayuntamientos su cumplimiento en relación al viario urbano.

Por otra parte, se establecen prohibiciones relativas a la iluminación, tales como: proyectores o láseres que emitan por encima de la horizontal salvo que iluminen elementos de especial interés histórico ${ }^{45}$, artefactos de publicidad aéreos nocturnos, la iluminación de grandes extensiones de playa o costa, la iluminación permanente de pistas de esquí, etc.

\section{b) Reglamentaciones técnicas en relación a instalaciones y aparatos de iluminación y ¿homologación de los aparatos que eviten la contaminación lumínica y ahorren energía? ${ }^{46}$}

La prevención y lucha contra la contaminación lumínica debe partir del establecimiento de unas condiciones técnicas de los aparatos de iluminación que garanticen su adaptación al principio de utilización de las mejores técnicas disponibles siempre que ello no conlleve costes excesivos, el cual rige en la prevención de otros tipos de contaminación, como por ejemplo la acústica ${ }^{47}$. La incorporación por las empresas de las tecnologías más avanzadas se erige como

\footnotetext{
45 En la Sentencia de 29 de marzo de 2005 del Tribunal Superior de Justicia de la Comunidad Valenciana el recurrente alegaba que la habilitación municipal de un «rayo láser» en una zona de ocio producía contaminación lumínica. Esta fundamentación fue rechazada por no haber quedado acreditada dicha contaminación lumínica. La prohibición de este tipo de iluminación en una legislación básica estatal o en la normativa autonómica hubiese evitado este tipo de pronunciamientos.

46 En esta materia hemos de tener en cuenta el recientemente aprobado Reglamento de Eficiencia Energética en Instalaciones de Alumbrado Exterior (R.D. 1890/2008, de 14 de noviembre).

47 Vera Jurado, Diego J.: Derecho Ambiental de Andalucía. Ed. Tecnos. 2005, págs. 286-287.
} 
parámetro de calidad del suministro eléctrico en la Ley reguladora del Sector Eléctrico ${ }^{48}$.

Así, en la mayoría de las legislaciones autonómicas sobre la materia se prevé que las instalaciones y los aparatos de iluminación se deben diseñar e instalar de manera que prevenga la contaminación lumínica y se favorezca el ahorro, el uso adecuado y el aprovechamiento de la energía. Se debe prestar especial atención a la inclinación, dirección, las características, el tipo de luminarias, etc.

Para potenciar el cumplimiento de los requisitos técnicos que se establezcan en cuanto a instalaciones y aparatos de iluminación que eviten la contaminación lumínica se prevé la posibilidad de otorgar un distintivo homologado que acredite dicha cualidad.

Este mecanismo de protección se asimila más a una técnica de mercado para la protección del medio ambiente y, en consecuencia, parece vincularse a su utilización voluntaria. Ello parece corroborarse por el hecho de que una de las obligaciones que se imponen a las Administraciones competentes es la de controlar que los alumbrados exteriores se realizan preferentemente con elementos que tengan acreditada su cualidad para reducir la contaminación lumínica y ahorrar energía y que la contratación administrativa tenga en cuenta ese distintivo de cualidad.

Considero que esto puede dar lugar a una errónea interpretación de la normativa para la prevención de la contaminación lumínica en la cual las exigencias técnicas o reglamentaciones técnicas referidas a las instalaciones o aparatos de iluminación deben ser de obligado cumplimiento para todos los fabricantes. El distintivo homologado de su cualidad ambiental sólo debe funcionar como una garantía de que las instalaciones o luminarias cumplen los requisitos técnicos exigidos.

En esta línea se ha regulado esta técnica del distintivo homologado en la CCAA de Cantabria. La misma tras recoger las reglamentaciones técnicas antes referidas incluye la competencia autonómica para homologar las luminarias que se pretendan instalar, no admitiendo el otorgamiento de ninguna licencia de obras o de apertura que no cumpla las citadas prescripciones técnicas ${ }^{49}$.

Este distintivo homologado debe convertirse en un requisito exigible a todo fabricante o instalador de luminarias, sin el cual no podrá contratar con la Administración pública competente ni con los particulares o empresas que requieran iluminación para exteriores.

\footnotetext{
48 Art. 48 de la Ley del Sector Eléctrico. Al respecto vid, GONZÁlEZ VARAS IBÁÑEZ, S.: «El suministro en el sector energético», en el libro colectivo Derecho de la Energía. Ed.La Ley. 2006 (págs. 172 y ss.).

49 Arts. 8, 12 y 13 de la Ley6/06, de 9 de junio, de Prevención de la Contaminación Lumínica de Cantabria.
} 
Esta afirmación la avala el hecho de que ya existen mecanismos de mercado para el control de la contaminación como puede ser la obtención de la etiqueta ecológica comunitaria ${ }^{50}$ para determinados productos, entre los que ya se incluyen las bombillas eléctricas. Al respecto la Decisión de la Comisión de 9 de septiembre de $2002^{51}$, por la que se establecen criterios ecológicos revisados para la concesión de la etiqueta ecológica comunitaria a las bombillas eléctricas, entre las que se incluyen las de un solo casquillo o de dos casquillos, que puedan conectarse a la red eléctrica pública. Entre los objetivos que se marca esta Decisión relativa a la concesión de la etiqueta ecológica a este tipo de productos figuran la disminución de daños o riesgos medioambientales derivados del consumo de energía, tales como, el calentamiento del planeta o el agotamiento de los recursos no renovables, mediante la reducción del consumo; así como, disminuir los daños o riesgos medioambientales derivados de la utilización de mercurio mediante la reducción de las emisiones totales de mercurio durante el ciclo de vida de las bombillas eléctricas.

En relación a este último objetivo hemos de tener en cuenta que las legislaciones autonómicas sobre contaminación lumínica vienen exigiendo la utilización prioritaria en los alumbrados exteriores de lámparas de vapor de sodio de alta presión y de baja presión, las cuales han de sustituir a las lámparas de vapor de mercurio en los procesos de renovación del alumbrado público. Con ello se pretende reducir la generación de residuos peligrosos y tóxicos al acabar la vida útil de las lámparas.

Si resulta que técnicamente las lámparas de vapor de sodio son menos contaminantes que las de vapor de mercurio se debería exigir por el legislador autonómico o estatal la implantación de aquel tipo de lámparas en aras del ahorro y eficiencia energética y de la protección contra la contaminación medio ambiental.

\section{c) Horario nocturno de iluminación}

La legislación sobre contaminación lumínica aprobada por la CCAA de Cataluña establece un régimen horario para el alumbrado, que ha sido seguido posteriormente por la legislación en dicha materia de la Comunidad Foral Navarra, las Islas Baleares y Cantabria.

\footnotetext{
50 Entre otros Martín Mateo, R.: Tratado de Derecho Ambiental. Vol. I. Ed. Trivium, SA, 1991 (pág. 424); Nuevos instrumentos de tutela ambiental (págs. 37 y ss.). SANZ RUBIALES, J.: «Sobre la naturaleza jurídica de la etiqueta ecológica», en el libro homenaje a MARTín MATEO, R. (págs. 3693 y ss.). GONZÁLEZ Ríos, I.: «Instrumentos de mercado en la tutela ambiental. Una visión actualizada sobre su implantación, en RAAP n. ${ }^{\circ}$ 64 (2006, págs. 215 y ss.). P. DOPAZO: «El etiquetado ecológico. Empresa y consumo». IV Congreso Nacional ADAME. Consumo y Derecho Ambiental. Alicante, 17-18 de diciembre de 2003. LOZANO CUTANDA, B.: Derecho Ambiental..., op, cit., págs. (484 y ss.).

51 Decisión 2002/747/CE, de la Comisión, de 9 de septiembre, por la que se establecen criterios ecológicos para la concesión de la etiqueta ecológica comunitaria a las bombillas eléctricas y se modifica la Decisión 1999/568/CE.
} 
Dos previsiones merecen ser destacadas al respecto, la primera, la obligación de mantener apagado tanto el alumbrado público como el privado en horario nocturno salvo por razones de seguridad, para iluminar calles, aparcamientos o zonas de paso, para usos comerciales, industriales, deportivos... durante el tiempo de actividad, o por razones justificadas. La segunda, que los Ayuntamientos regularán un régimen propio de alumbrado para acontecimientos nocturnos singulares, festivos, feriales, deportivos, etc.

A estas determinaciones, las CCAA de Baleares y Navarra añaden una importante previsión, la necesidad de reducir el flujo de luz en el alumbrado público a determinadas horas de la noche en las que la actividad ciudadano y la intensidad del tráfico disminuyen considerablemente.

Para la aplicación de estas previsiones sobre régimen horario de la iluminación nocturna es necesaria la colaboración municipal y autonómica en la medida que el establecimiento de las franjas horarias en las que debe apagarse o reducirse la intensidad de la iluminación van a estar en función del tipo de municipio, de la estación del año, etc.

\section{C) El control de la contaminación lumínica mediante el otorgamiento de autorizaciones}

Las características de los alumbrados exteriores e interiores si generan intrusión lumínica en el exterior, ajustadas a la normativa autonómica sobre medio ambiente, debe hacerse constar en los proyectos técnicos que deben acompañar a las solicitudes de autorizaciones ambientales, licencias de obras o de actividad y en los proyectos de urbanización.

\section{D) Control de la contaminación lumínica a través de la contratación administrativa ${ }^{52}$}

Otra técnica de gran relevancia en el control de este fenómeno contaminante es la inclusión en los pliegos de cláusulas administrativas particulares de los contratos de obras, suministro y servicios de los requisitos que debe cumplir el alumbrado exterior para ajustarse a la prevención y corrección de la contaminación lumínica.

El cumplimiento de dichos requisitos quedará acreditado presentando el distintivo homologado de cualidad de las luminarias.

52 Entre otros, Lozano Cutanda, B.: Derecho Ambiental..., op, cit. (2006, págs. 450 y ss.). 


\section{Técnicas de control}

\section{A) La obligación de adaptación de los alumbrados exteriores}

La lucha contra la contaminación lumínica debe partir de la obligación de adaptar los alumbrados exteriores que no respeten la normativa sobre protección contra dicho tipo de contaminación, como ya exige la normativa de la CCAA de Cataluña, la Foral Navarra, la Balear y Cantabria.

El problema radica en que la lucha contra la contaminación lumínica no puede verse territorialmente fraccionada en función de que la respectiva CCAA haya o no legislado en la materia o de que los municipios voluntariamente se sumen a la lucha contra este tipo de contaminación. Se exige profundizar en la regulación estatal básica en la materia, para lo cual se ha desaprovechado la ocasión con la aprobación de la Ley de Calidad del Aire y protección de la atmósfera. Ello lo corrobora además el hecho de que la lucha contra la contaminación lumínica debe ir asociada a la búsqueda de la máxima eficiencia energética.

\section{B) La inspección y el régimen sancionador}

Las legislaciones autonómicas sobre contaminación lumínica distinguen entre infracciones muy graves, graves y leves, estableciendo sanciones que oscilan entre un mínimo de unos 150 euros, para infracciones leves, un máximo de unos 30000 euros para las infracciones muy graves. No obstante, en Andalucía, la Ley de Gestión Integrada de la Calidad Ambiental no recoge entre las infracciones muy graves ninguna relativa a la contaminación lumínica, refiriéndose expresamente a la misma como una infracción grave cuando se produzca el «incumplimiento de las restricciones y limitaciones de uso en materia de contaminación lumínica». Este tipo de infracciones se sancionan con multas que oscilan entre los 30000 y los 60000 euros, con lo cual se aprecia un aumento de la cuantía considerable si comparamos esta sanción con las previstas en el resto de legislaciones autonómicas. El incumplimiento de las obligaciones impuestas por dicha ley que no estén expresamente tipificadas como graves o muy graves se calificarán como leves y se sancionarán como tales.

La potestad sancionadora, así como, la de inspección y control se distribuye entre la CCAA y los entes locales en Comunidades Autónomas como Cataluña y Cantabria. De forma novedosa, la legislación sobre prevención de la contaminación lumínica de Cantabria establece que la competencia para imponer sanciones por infracciones graves y leves será indistinta de los Ayuntamientos y del Consejero responsable del medio ambiente. Por su parte, en la CCAA Balear el ejercicio de aquellas potestades corresponde al Consejo Insular y a los entes locales. Andalucía y la Comunidad Foral Navarra, aplicando un criterio 
más razonable, atribuyen aquellas potestades a los órganos autonómicos competentes por razón de la materia.

En el ejercicio de la potestad sancionadora se observa una importante incongruencia en algunas de las legislaciones autonómicas. La distribución de esta competencia entre la Administración autonómica y la Administración local carece de sentido cuando en gran medida este tipo de contaminación se produce a través del alumbrado público local. Al menos respecto de este u otros alumbrados como los de edificios o bienes locales, la competencia para sancionar por contaminación lumínica no debería estar en manos de los mismos Ayuntamientos. En esta materia Andalucía ha atribuido la competencia a la CCAA, como hemos comentado.

Por otro lado, nos encontramos con un importante vacío en materia sancionadora en relación con aquellas CCAA que no tienen aprobada normativa propia en la materia, en las cuales las infracciones y sanciones deben venir tipificadas en Ordenanzas municipales en el marco de lo previsto en la Ley de Reguladora de Bases de Régimen Local. En tal caso, obviamente el ejercicio de la potestad sancionadora corresponde a los municipios con el absurdo que ello conlleva en relación al cumplimiento de una normativa sobre prevención de la contaminación lumínica, en lo relativo al alumbrado público.

Un aspecto novedoso en esta materia es la posibilidad de que la inspección y control lo realicen entidades colaboradoras. La razón de ser de esta medida está en la búsqueda de la inspección y control realizados por expertos, tan necesarios en este tipo de contaminación, pero a los que no puede reconocérseles la condición de autoridad ${ }^{53}$.

\section{Medidas económicas}

La legislación autonómica sobre contaminación lumínica de Cataluña, las Islas Baleares, Navarra y Cantabria no es ajena al importante problema del costo que para los municipios supone la lucha contra la contaminación lumínica, desde la necesaria adaptación del alumbrado público a las exigencias de sus respectivas legislaciones.

Por ello todas ellas han previsto un régimen de ayudas para promover la adaptación de los alumbrados exteriores existentes a las exigencias legales de

\footnotetext{
53 Vid entre otros: CANAls AmetLleR, D.: «Entidades colaboradoras de la Administración pública en el ámbito de la protección del medio ambiente. Las entidades ambientales de control», en la obra colectiva coordinada por Esteve PARDo, J.: Derecho del Medio Ambiente y Administración Local. 2. a edición. Fundación Democracia y Gobierno Local. Barcelona (2006, págs. 305 y ss.). CASADO CASADO, L.: «Las Administraciones públicas ante la contaminación...», op, cit., págs. 343 y ss. ESTEVE PARDO, J: Tratamiento del riesgo tecnológico en el Derecho ambiental. Ariel. Barcelona (1999, pág. 23 y ss.). BETANCOR RoDRíGUEZ, A: Instituciones de Derecho Ambiental. La Ley. Madrid (2001, pág. 1050).
} 
prevención y lucha contra la contaminación lumínica. Las ayudas se otorgarán preferentemente para la adaptación de los alumbrados incluidos en zonas o áreas clasificadas como E1.

Para hacer frente a este tipo de ayudas la CCAA de Cataluña, las Islas Baleares y Cantabria crean un fondo económico cuyo objetivo exclusivo es la protección del medio contra la contaminación lumínica.

Estas medidas económicas deberían potenciarse desde una normativa básica estatal desde el momento en que con las mismas se tiende a conseguir la eficiencia energética.

\section{LA CONTAMINACIÓN LUMÍNICA: IMPLICACIONES URBANÍSTICAS Y DEMANIALES}

Vistos los títulos competenciales en que pueden apoyarse los Entes Locales para regular el fenómeno de la contaminación lumínica, en las CCAA que carecen de normativa propia en la materia, la mayoría de ellas, deben ser los municipios los que entren de lleno en el tema a fin de no retrasar más la prevención y control de este tipo de contaminación ${ }^{54}$. Claro está que los Entes locales tienen mayores limitaciones al respecto. No obstante, analicemos las distintas posibilidades que les brinda la normativa urbanística, demanial y sectorial a los mismos para intervenir en dicho fenómeno contaminante ${ }^{55}$.

\section{El alumbrado público ${ }^{56}$ y otras redes de iluminación}

La legislación urbanística autonómica no es ajena a la protección y prevención ambiental ${ }^{57}$. Así, las E de $\mathrm{M}$ y el articulado de las legislaciones autonómicas en la materia son claros desarrollos del art. 45 de la CE, en un empeño por desarrollar el derecho de todos a disfrutar de un medio ambiente adecuado para el desarrollo de la persona. El uso racional y sostenible de los recursos natura-

\footnotetext{
54 Si bien la contaminación lumínica debe atajarse desde regulaciones de ámbito nacional o mejor aún comunitario e internacional.

55 Sobre el papel de los municipios en cuanto a la contaminación lumínica, entre otros, D. ENTRENA RUIZ: «La prevención contra la contaminación lumínica mediante la ordenación del territorio y urbanismo», en Ecosostenible (2005, pág. 25); sobre el papel de aquellos en cuanto a la consecución de la suficiencia energética ORTIZ GARCÍA, M.: «La ciudad solar. Soporte jurídico», en el libro colectivo Derecho de la energía, op, cit., pág. 826. CASADO CASADO, L.: «El papel de los municipios...», op, cit., págs. 143 y ss.

56 Entre otros, Mestre Delgado, J.F.: « Alumbrado público», en Derecho Local Especial. Tomo I. El Consultor de los Ayuntamientos y de los Juzgados. Madrid. 1997.

57 La incorporación de la variable ambiental al planeamiento urbanístico y territorial se ha puesto de manifiesto, entre otros, por Lozano CuTAnda, B.: Derecho Ambiental Administrativo. Ed. Dykinson (2006, pág. 390 y ss.).
} 
les, la protección del medio ambiente y del paisaje constituyen fines específicos de dichas legislaciones ${ }^{58}$.

Esta protección del medio ambiente debe interpretarse como una protección integral que incluya uno de sus aspectos más novedosos como es la contaminación lumínica. Desde esta perspectiva la normativa urbanística puede incidir en la protección contra la contaminación lumínica a través del planeamiento y de la disciplina urbanística.

Desde el momento en que uno de los principales agentes causantes de este tipo de contaminación lo constituye el alumbrado público, el planeamiento urbanístico puede jugar un papel destacado en la protección del medio ambiente y, en consecuencia, la prevención y control de la contaminación lumínica debe realizarse a través del planeamiento urbanístico. El PGOU, como señalan las legislaciones autonómicas, debe optar por un modelo de ordenación que garantice la «funcionalidad, economía y eficacia en las redes de infraestructura para la prestación de servicios urbanos», tales como, el alumbrado público o el suministro de energía eléctrica ${ }^{59}$. Además, los Planes Parciales ${ }^{60}$ deben prever el trazado y características de las galerías y redes propias del sector de energía eléctrica y alumbrado, entre otros servicios ${ }^{61}$. Mediante dicho trazado y características pueden controlarse importantes aspectos de la contaminación lumínica como los relativos a la correcta colocación o instalación de las luminarias para el alumbrado público ${ }^{62}$.

También los Planes Especiales constituyen un importante instrumento para la prevención de la contaminación lumínica desde el momento en que entre sus finalidades fija la de «conservar, proteger y mejorar el medio urbano» y en especial el patrimonio arquitectónico, histórico y cultural, con esta finalidad pueden aprobarse Planes Especiales que mejoren y protejan el medio urbano de la contaminación lumínica, actuando sobre la iluminación de viales, o de edificios de relevancia histórica, arquitectónica o cultural. En este último caso, pueden jugar un papel relevante también los Catálogos, previstos en algunas legislaciones urbanísticas autonómicas, que tienen por objeto complementar las determi-

\footnotetext{
58 Sirva como ejemplo, el art. 3.1,a, b de la Ley 7/02, de 17 de diciembre, de Ordenación Urbanística de Andalucía; art. 3 de la Ley 2/02, de 14 de marzo, de Urbanismo de Cataluña; art. 3 de la Ley 9/01, de 17 de julio, del Suelo de la Comunidad de Madrid; art. 4 de la Ley 5/99, de 8 de abril, de Urbanismo de Castilla y León.

59 V.g, art. 9.A.e) de la Ley 7/02, de 17 de diciembre, de Ordenación Urbanística de Andalucía.

60 Previstos en la Ley 7/02, de 17 de diciembre, de Ordenación Urbanística de Andalucía para el desarrollo del suelo urbano no consolidado y del suelo urbanizable (art. 13).

61 En el mismo sentido el art. 53.2 de Reglamento de Planeamiento Urbanístico.

62 Martín Retortillo, Cirilo: Las obligaciones mínimas de los Ayuntamientos. Madrid, 1956, pág. 236, sostiene que «las instalaciones y el alumbrado no deben efectuarse de una manera caprichosa sino que deberán ajustarse a un proyecto meditado con método y coordinación bien estudiada para de esta manera lograr que cada calle tenga el alumbrado que racionalmente le corresponda y con criterio de generalidad e igualdad que evite mortificantes privilegios o preferencias». En la misma línea la comentada Sentencia de 19 de diciembre de 2006 del Tribunal Superior de Justicia de la Comunidad Valenciana (Pte. María D. Iruela Jiménez).
} 
naciones de los instrumentos de planeamiento relativas a la conservación, protección o mejora del patrimonio urbanístico, arquitectónico, histórico, cultural, natural y paisajístico ${ }^{63}$.

Por otro lado, como complemento de los instrumentos de planeamiento, las Ordenanzas Municipales de Edificación ${ }^{64}$ pueden tener por objeto regular aspectos estéticos exigibles para la autorización de actos de construcción, edificación y usos susceptibles de realización en inmuebles ${ }^{65}$. Mediante ellas se puede incidir en el alumbrado de edificios, comercios, patrimonio histórico, arquitectónico, natural o paisajístico, modulando el tipo de instalaciones de iluminación a implantar, o determinando prohibiciones respecto de anuncios reflectantes, etc.

La disciplina urbanística también juega un papel esencial en la protección contra la contaminación lumínica. Prueba de ello es que las legislaciones autonómicas en la materia vienen exigiendo que el proyecto que se presente para obtener la licencia urbanística sea acorde con la normativa sobre protección contra la contaminación lumínica.

La normativa urbanística de las distintas CCAA viene exigiendo la licencia urbanística para los actos de construcción, edificación e instalación y de uso del suelo, del subsuelo y del vuelo, entre los que pueden incluirse la instalación de alumbrado exterior.

En consecuencia, cualquier instalación de iluminación exterior puede ser controlada en cuanto al efecto que produce respecto de la contaminación lumínica en función al objetivo que toda la normativa urbanística autonómica se marca de protección del medio ambiente. El problema está en que para que esa protección sea realmente efectiva se requiere una zonificación del territorio y algunos criterios claros sobre el tipo de luminarias a utilizar, el régimen de horario nocturno, etc. Estas determinaciones, a falta de normativa específica en la materia, deberían recogerse en el planeamiento urbanístico o en Ordenanzas municipales.

No obstante, el control a través del otorgamiento de la licencia urbanística se torna escaso o relativo si tenemos en cuenta que las grandes infraestructuras contaminantes en materia lumínica son de titularidad de una Administración pública y, por regla general, están exentas de exigir la previa licencia municipal $^{66}$. Nos referimos al alumbrado público y a las instalaciones de iluminación de costas, carreteras o puertos.

\footnotetext{
$63 \mathrm{Vg}$, art. 16.1 Ley 7/02, de 17 de diciembre, de Ordenación Urbanística de Andalucía.

64 Cuya formulación y aprobación corresponde a los municipios de conformidad con el art. 25 de la Ley 7/02, de 17 de diciembre, de Ordenación Urbanística de Andalucía.

65 Así, el art. 24 de la Ley 7/02, de 17 de diciembre, de Ordenación Urbanística de Andalucía.

66 Las legislaciones urbanísticas autonómicas exceptúan de la exigencia de licencia municipal las obras, usos o instalaciones realizadas por el propio municipio, así como, las realizadas por una Administración pú-
} 
Por lo que respecta al alumbrado público, la no exigencia de licencia municipal para la realización de las obras necesarias para su implantación no exime al municipio del cumplimiento de todos los requisitos exigibles para obtener dicha licencia ${ }^{67}$, y entre ellos se deben incluir todos los relativos a la protección contra la contaminación lumínica, que deben venir reflejados en el correspondiente instrumento de planeamiento urbanístico en relación principalmente al suelo urbano y al urbanizable o en la correspondiente ordenanza municipal.

Por su parte, la iluminación de costas, carreteras, puertos, aeropuertos, y en general, cualquier tipo de iluminación destinada a garantizar la seguridad ciudadana o del tráfico, ha quedado excluida de la aplicación de las determinaciones sobre protección contra la contaminación lumínica por las legislaciones de aquellas CCAA que han regulado esta materia. Ello no impide que la legislación sectorial en la materia establezca unas normas mínimas sobre protección contra este tipo de contaminación, al igual que se prevén determinaciones para evitar otros tipos de impactos ambientales.

De hecho, el excluir sin más la aplicación de todas las determinaciones sobre protección contra la contaminación lumínica respecto de aquel tipo de iluminaciones relativiza mucho la lucha contra la misma. Y ello porque estamos hablando de instalaciones, principalmente las de iluminación de carreteras, aeropuertos, puertos o costas que pueden generar un importante impacto lumínico. Está claro que no se puede limitar la intensidad de la luz de un faro, que cumple funciones esenciales en cuanto al tráfico marítimo, pero si puede establecerse el tipo de luminarias que deben iluminar un puerto; o reducir la intensidad en la iluminación de carreteras a determinadas horas de la noche.

Si nos centramos en algunas de estas normas sectoriales nos encontramos con referencias claras a la iluminación de los bienes a los que se refieren.

A este respecto hemos de tener en cuenta la prohibición que realiza la Ley de Costas de realizar publicidad a través de carteles o vallas audiovisulaes ${ }^{68}$. Además, las compañías suministradoras de energía eléctrica exigirán para la contratación de sus servicios, la presentación del título administrativo exigible por dicha Ley para la realización de obras o instalaciones en las playas y zona marítimo terrestre o mar ${ }^{69}$.

\footnotetext{
blica cuando tengan la calificación de obras de interés general o cuando se trate de obras ordinarias si la legislación sectorial establece un procedimiento especial de armonización o compatibilidad con la ordenación urbanística. Sirva de ejemplo el art. 170 de la Ley 7/02, de 17 de diciembre, de Ordenación Urbanística de Andalucía.

67 En este sentido, el art. 169.4 de la Ley 7/02, de 17 de diciembre, de Ordenación Urbanística de Andalucía establece que cuando los actos de construcción o edificación, instalación y uso del suelo sean promovidos por los Ayuntamientos en su propio término municipal, el acuerdo municipal que los autorice o apruebe estará sujeto a los mismos requisitos y producirá los mismos efectos que la licencia urbanística, sin perjuicio de lo dispuesto en la legislación de régimen local.

68 Art. 38 de la Ley 22/88, de 28 de julio de Costas.

69 Art. 39 Ley 22/88, de 28 de julio de Costas.
} 
En la medida en que para la realización de obras o instalaciones en las zonas de dominio público de las playas se necesita no sólo el correspondiente título demanial, sino también, la licencia urbanística de obras, será al otorgar esta cuando el municipio debe controlar que las instalaciones se ajustan a exigencias de prevención de la contaminación lumínica.

Además, para la ocupación o utilización del dominio público marítimo terrestre se exige un proyecto, el cual deberá formularse conforme al planeamiento urbanístico que desarrollen y de conformidad con las normas que apruebe la Administración competente en función del tipo de obra y de su emplazamiento ${ }^{70}$. Entre otros aspectos deberán determinar «la adaptación de las obras al entorno en que se encuentren situadas y, en su caso, la influencia de las obras sobre la costa...» ${ }^{71}$.

Estas previsiones pueden servir para introducir la prevención de la contaminación lumínica respecto de la iluminación de las costas. Así, los proyectos de iluminación de costas deberán ajustarse a la planificación urbanística, procurando que las instalaciones de iluminación se adapten al entorno y que la influencia sobre el mar, plantas y animales sea mínima. A ello puede ayudar la exigencia de que «los paseos marítimos se localicen fuera de la ribera del mar», lo que unido a una correcta utilización de las fuentes de iluminación pueden evitar efectos perniciosos para la flora o la fauna marítima.

Por otro lado, la articulación de obras de interés general, entre las que pueden incluirse la iluminación de costas y señales marítimas y de carreteras o puertos, con el planeamiento urbanístico se prevé en las respectivas legislaciones sectoriales. Estas obras de interés general quedan exentas del control preventivo mediante la obtención de la correspondiente licencia urbanística de obras.

Así, la iluminación de costas y señales marítimas es competencia de la Administración estatal ${ }^{72}$ y tienen la consideración de obras de interés general ${ }^{73}$. Respecto de este tipo de obras se exige para su ejecución solicitar informe a la CCAA y Ayuntamiento en cuyo ámbito territorial incidan, a fin de que notifiquen la conformidad o disconformidad de la obra con los instrumentos de planificación del territorio y planeamiento urbanístico. En caso de disconformidad, el Ministerio de Medio Ambiente elevará el expediente al Consejo de Ministros que decidirá si procede ejecutar el proyecto, y en tal caso, ordenará la iniciación del procedimiento de modificación o revisión del citado planeamiento. Dichas obras, además, no se sujetan a licencia urbanística municipal ${ }^{74}$.

\footnotetext{
70 Art. 44.1 Ley 22/88, de 28 de julio de Costas.

71 Art. 44.2 Ley 22/88, de 28 de julio de Costas.

72 Art. 110.j) de la Ley 22/88, de 28 de julio de Costas.

73 Art. 11.1.c) Ley 22/88, de 28 de julio de Costas.

74 Art. 111.2 Ley 22/88, de 28 de julio de Costas
} 
En el mismo sentido se pronuncia la Ley de Carreteras respecto de la construcción de carreteras o variantes no incluidas en el planeamiento urbanístico de los núcleos de población a que afecte, en cuyo caso será el Ministerio de Fomento el que remita el estudio informativo a las CCAA y Corporaciones Locales afectadas ${ }^{75}$.

Por su parte, la Ley de Puertos del Estado y de la Marina Mercante prevé la articulación entre la planificación urbanística y la ordenación portuaria mediante la figura de los Planes Especiales o figura equivalente que establezca el sistema general portuario, que si bien se aprueba por la Administración con competencia urbanística, si la autoridad portuaria manifiesta su disconformidad con el mismo, y no se llega a un acuerdo al respecto, decidirá el Consejo de Ministros.

Así, las obras necesarias para realizar la iluminación de los Puertos estatales deben ajustarse a ese Plan Especial de ordenación del espacio portuario. Además, las obras de construcción, reparación y conservación que se realicen en el dominio público portuario no se someten a licencia municipal. Los proyectos de construcción de nuevos puertos se sujetarán al procedimiento de declaración de impacto ambiental ${ }^{76}$.

La planificación, coordinación y control del sistema de señalización marítima español, así como, el fomento de la formación, investigación y desarrollo tecnológico en estas materias corresponde a Puertos del Estado bajo la supervisión del Ministerio de Fomento ${ }^{77}$.

Entre los servicios generales del puerto, o sea, los servicios comunes de titularidad de la autoridad portuaria de los que se benefician los usuarios sin necesidad de solicitud figuran: los de señalización y balizamiento ${ }^{78}$ y «el servicio de alumbrado de las zonas comunes» ${ }^{79}$.

En cuanto a la utilización del dominio público portuario estatal destaca la prohibición de utilizaciones u ocupaciones que se destinen a publicidad comercial a través de carteleras o vallas, medios audiovisuales situados en el exterior de los edificios ${ }^{80}$. La Ley sobre Régimen Económico y Prestación de Servicios

\footnotetext{
75 Art. 10.2 de la Ley 25/88, de 29 de julio, de Carreteras.

76 Art. 20.2 de la Ley 27/92, de 24 de noviembre, de Puertos.

77 Art. 25 de la Ley 27/92, de 24 de noviembre de Puertos.

78 Arts.91 y ss. de la Ley 48/03, de 26 de noviembre, de Régimen Económico y Prestación de Servicios de los Puertos de Interés General. Para la defensa y protección del servicio de señalización marítima, a fín de garantizar su adecuada identificación y uso, el Ministerio de Fomento a propuesta de Puertos del Estado establecerá las limitaciones y servidumbres a las propiedades colindantes respecto a ayudas visuales, condicionamiento de altura y distancia, colores y luminosidad de las luces del entorno, sobre la luminancia de fondo (art. 91.6).
}

79 Art. 58 c) y e) de la Ley 48/03, de 26 de noviembre, de Régimen Económico y Prestación de Servicios de los Puertos de Interés General.

80 Art. 94.3 de la Ley 48/03, de 26 de noviembre, de Régimen Económico y Prestación de Servicios de los Puertos de Interés General. 
de los Puertos de Interés General incluye una previsión expresa sobre prevención y lucha contra la contaminación en el dominio público portuario que debería ampliarse a la prevención de la contaminación lumínica, dado, además, la influencia negativa que aquella puede tener en la señalización marítima ${ }^{81}$.

A modo de conclusión, en relación a las previsiones de iluminación recogidas en la legislación de Costas, Carreteras y Puertos podemos decir que no cabe duda que las exigencias para prevenir la contaminación lumínica no pueden venir impuestas exclusivamente desde el planeamiento territorial o urbanístico, en donde ejercen sus competencias las CCAA y los municipios, en la medida en que importantes redes de iluminación que causan esa contaminación lumínica (iluminación de costas, puertos, carreteras) podrían implantarse por mera decisión del Consejo de Ministros sin tener que seguir las determinaciones urbanísticas incluidas en el planeamiento. La exigencia de prevenir la contaminación lumínica debe venir impuesta a nivel de legislación estatal básica en materia de protección del medio ambiente, cuyas determinaciones deben coordinarse con las legislaciones sectoriales de costas, puertos, carreteras, etc. Sólo en aquellos aspectos donde no quepa la adaptación de las previsiones de la legislación sectorial a la normativa básica sobre contaminación lumínica por razones de seguridad pública o del tráfico (aéreo, marítimo o terrestre) se admitirán fuentes de luz que generen contaminación lumínica.

La exclusión que las legislaciones autonómicas realizan respecto a la aplicación de las mismas en cuanto a la contaminación lumínica producida por grandes infraestructuras de iluminación, no debe impedir que aquellas queden también sujetas a algunas determinaciones básicas sobre prevención de tal tipo de contaminación.

\section{La utilización del dominio público local con instalaciones de iluminación 82}

El alumbrado público del viario urbano, de parques y edificios públicos locales, así como, el correspondiente a bienes propiedad de otras Adminis-

\footnotetext{
81 Art. 129.1 Ley 48/03, de 26 de noviembre, de Régimen Económico y Prestación de Servicios de los Puertos de Interés General.

82 Vid., entre otros, GONZÁLEZ Ríos, I.: El dominio público municipal. Régimen de utilización por los particulares y compañías prestadoras de servicios. 2. ${ }^{\mathrm{a}}$ ed. Ed. Comares, Granada (2005). BASSOLS COMA MARTín: Las obras públicas y el urbanismo. Los actos de uso del suelo y la ejecución de obras promovidas por la Administración del Estado. MOPTMA. Madrid. 1994. COMES SIERRA, S.: «Legislación y Jurisprudencia local por utilización privativa o aprovechamiento especiales constituidos en el suelo, subsuelo o vuelo de vía pública municipal a favor de empresas explotadoras de servicios», en Primeras Jornadas de Energía y Derecho. Ed. Ente Vasco de Energía, 1988. DeSPAUX MighEL: «Técnicas jurídicas, clásicas y modernas de utilización del suelo, del subsuelo y del espacio». RDY n. ${ }^{\circ} 6$ (1968). GARCÍA BRAGADO, R.: « El establecimiento de infraestructuras. Expropiación, dominio público, urbanismo y medio ambiente». En Derecho de las Telecomunicaciones, La Ley.1997. LóPEZ PELLICER, J.A.: «Uso y aprovechamiento del dominio público local», en Libro Homenaje al Prof. J. Luis Villar Palasí. Ed. Cívitas, SA. Madrid.1989.
} 
traciones públicas (travesías, tramos urbanos, edificios públicos...) tiene la consideración de bienes de dominio público al amparo del art. 5.1 de la Ley de Patrimonio de las Administraciones Públicas ${ }^{83}$ por su afectación a un servicio público. Dicha ley recoge una serie de principios que deben regir la gestión y administración de los bienes y derechos demaniales, siendo de destacar, en lo que por ahora nos interesa, el principio de «adecuación y suficiencia de los bienes para servir al uso general o al servicio público a que estén destinados».

Así, por lo que respecta al alumbrado público esa adecuación y suficiencia deben ser parámetro para que las instalaciones de alumbrado cumplan con los requisitos exigidos por una normativa específica sobre prevención de la contaminación lumínica. El cumplimiento de dicho principio de gestión y administración de bienes demaniales debe llevar a las Administraciones públicas titulares de los alumbrados anteriormente reseñados a exigir unos determinados condicionamientos respecto de las luminarias a utilizar, su localización e inclinación, etc.

Estas exigencias respecto a las instalaciones de alumbrado público si bien deben cumplirlas todas las Administraciones, no cabe duda que el papel más destacado corresponde aquí a los municipios, que son los titulares de la principal red de alumbrado público de la ciudad. La calificación de bienes de dominio público de dicho alumbrado se recoge también en la Ley de Bases de Régimen Local $^{84}$ que lo considera como un servicio público cuya prestación es obligatoria en todos los municipios ${ }^{85}$. Desde la consideración del alumbrado público municipal como servicio público y de las instalaciones destinadas al mismo como bienes de dominio público de titularidad municipal, se observa que el control de la contaminación lumínica, entre tanto, no se apruebe la respectiva legislación autonómica en todas las CCAA y a falta de una legislación estatal básica que regule de forma completa el tema, está principalmente en manos de los municipios.

Pero no se nos debe escapar, que el coste económico que conlleva la sustitución de los actuales alumbrados públicos altamente contaminantes, va a frenar la acción municipal. Por ello, la lucha contra la contaminación lumínica debe venir impuesta por una normativa autonómica o, preferentemente básica estatal, que prevea el régimen de ayudas necesarias para que los municipios no sólo planifiquen para el futuro unas instalaciones de alumbrado menos contaminantes lumínicamente hablando, sino que, puedan sustituir la actual red de iluminación.

83 Ley 33/03, de 3 de noviembre, de Patrimonio de las Administraciones Públicas.

84 Art. 79 de la Ley 7/85, de 2 de abril, de Bases de Régimen Local.

85 Art. 26.1.a) de la Ley 7/85, de 2 de abril, de Bases de Régimen Local. Al respecto, TRILLO-FIGUEROA Martínez Conde, J., De Borja LóPez Jurado Escribano, F.: La regulación del sector eléctrico. Ed. Cívitas, SA. Madrid.1994, (pág. 61). 
Por otro lado, la contaminación lumínica que produzcan las vallas publicitarias, anuncios, escaparates, fachadas luminescentes, etc, siempre que, bien la valla publicitaria, o bien, la luz que desprenden invadan el dominio público local, el vuelo de bienes locales tales como aceras, viales, parques, etc, podrá ser controlado por los Ayuntamientos aplicando el régimen de utilización de los bienes de dominio público ${ }^{86}$. En tal sentido, la Ley de Patrimonio de las Administraciones Públicas establece como regla general la necesidad de título habilitante otorgado por la autoridad competente para utilizar bienes de dominio público en forma que exceda el derecho de uso que, en su caso, corresponda a todos 87 .

No cabe duda que la invasión lumínica que provocan determinados anuncios o carteles, publicitarios o no, privados constituyen un uso común especial, en la ya tradicional definición que del mismo dio el Reglamento de Bienes de las Entidades Locales ${ }^{88}$, o sea, aquel uso en el que concurren circunstancias especiales por su peligrosidad, intensidad del uso o cualquiera otra semejante ${ }^{89}$. Entre esas otras circunstancias semejantes pueden añadirse otras características tales como la «obtención de una rentabilidad singular» ${ }^{90}$.

\section{LA EFICIENCIA ENERGÉTICA COMO ELEMENTO CLAVE EN LA LUCHA CONTRA LA CONTAMINACIÓN LUMÍNICA $^{91}$}

\section{Normativa reguladora del sector eléctrico}

La necesaria integración de la protección contra la contaminación lumínica con otras políticas sectoriales que inciden directamente en la misma como la energética, más concretamente las políticas relacionadas con el sector eléctrico, exigen el análisis de la normativa reguladora del mismo.

En la legislación reguladora del sector eléctrico ${ }^{92}$ podemos, también, encontrar varios fundamentos para luchar contra la contaminación lumínica.

\footnotetext{
86 Al respecto, entre otras: la Sentencia del Tribunal Supremo de 7 de mayo de 1986 (ar.3049; Pte. J.M. Reyes Monterreal); la Sentencia de 11 de febrero de 1991 (ar.1178; Pte. J. I. Jiménez Hernández).

87 Art. 84 de la Ley de Patrimonio de las Administraciones Públicas.

88 Real Decreto 1372/86, 13 de junio, Reglamento de Bienes de las Entidades Locales.

89 Art. 75.1.b) Reglamento de Bienes de las Entidades Locales.

90 Así, se recoge en la definición que de aprovechamiento especial de bienes estatales recoge el art. 85.2 de la Ley de Patrimonio de las Administraciones Públicas de 2003.

91 Sobre la materia puede consultarse la excelente recopilación normativa realizada por ALENZA GARCÍA, J. F., y SARAsíbar IRIARTE, M.: Cambio climático y energías renovables. Ed. Thonson/Cívitas. 2007. CASADO CASADO, L.: «El papel de los municipios...», op, cit., págs. 143-144, 156 ss.

92 Ley 54/97, de 27 de noviembre, del Sector Eléctrico.
} 
El primero podemos extraerlo de las finalidades que pretende conseguir esta Ley, entre las que se sitúa «la ordenación del suministro de energía eléctrica a las necesidades de los consumidores y la racionalización, eficiencia y optimización de las mismas». Dicha finalidad encaja perfectamente en el objetivo de lucha contra la contaminación lumínica. Desde la normativa reguladora del sector eléctrico se puede, pues, incidir en la prevención de la contaminación lumínica.

El segundo, se deduce del hecho de que la planificación eléctrica, de competencia estatal, debe referirse a diversos aspectos, entre los que destaca «la mejora de la eficiencia y protección del medio ambiente»o «los criterios de protección mediambiental que deben condicionar las actividades de suministro de energía eléctrica» ${ }^{93}$. No cabe duda de que la mejora en la protección medioambiental pasa por el ahorro energético, lo que redundará en una menor contaminación de la atmósfera, por reducción de emisiones contaminantes, incluidas las emisiones lumínicas ${ }^{94}$.

Además, la planificación eléctrica debe coordinarse con la planificación territorial y urbanística ${ }^{95}$, en la que como hemos indicado más arriba deben contenerse previsiones específicas de lucha contra este novedoso tipo de contaminación.

En tercer lugar, la citada normativa reconoce el derecho de las empresas distribuidoras y comercializadoras a exigir que las instalaciones y aparatos receptores de los usuarios reúnan las condiciones técnicas y de construcción que se determinen, así como, el buen uso de las mismas y el cumplimiento de las condiciones establecidas para que el suministro se produzca sin deterioro o pérdida de su calidad ${ }^{96}$. Además, las instalaciones de producción, transporte y distribución de energía eléctrica deben cumplir las normas técnicas y de seguridad de las instalaciones eléctricas. Dichas reglamentaciones técnicas tendrán entre otros objetivos «proteger el medio ambiente y los derechos e intereses de los consumidores y usuarios y conseguir los niveles adecuados de eficiencia en el uso de la electricidad ${ }^{97}$. Estas reglamentaciones técnicas exigidas en la normativa sectorial redundan en la calidad y seguridad del suministro eléctrico, pero también en la protección contra la contaminación lumínica.

\footnotetext{
93 Art. 4.2.b), g) Ley 54/97, de 27 de noviembre, del Sector Eléctrico.

94 Sobre la ambivalencia conceptual de la contaminación atmosférica, entre otros: DE MIGUEL PERALES, C.: Derecho Español del Medio Ambiente. Ed. Cívitas. Madrid. (2000, pág. 127): Vera JurAdo, D.: Derecho Ambiental de Andalucía. Ed. Tecnos (2005, pág. 303).

95 Dicha coordinación debe realizarse en los términos previstos en el art. 5 de la Ley 54/97, de 27 de noviembre, del Sector Eléctrico.

96 Art. 45.3.1 Ley 54/97, de 27 de noviembre, del Sector Eléctrico.

97 Art. 51.2 de Ley 54/97, de 27 de noviembre, del Sector Eléctrico.
} 
Como puede observarse la protección medio ambiental no es ajena a la regulación del sector eléctrico, en la cual se prevén diversos mecanismos que podrían utilizarse para la prevención de la contaminación lumínica: la planificación del sector guiada por la eficiencia y ahorro energético y su coordinación con el planeamiento urbanístico, imposición de exigencias en las reglamentaciones técnicas que deben cumplir las instalaciones de distribución de energía eléctrica en cuanto al material y diseño para que potencie el ahorro de energía, etc; o la posibilidad de que las empresas distribuidoras y comercializadoras exijan que las instalaciones y aparatos receptores de las Administraciones públicas y particulares reúnan las condiciones técnicas y de construcción que se fijen con el objeto de evitar la contaminación lumínica y ahorrar energía.

Como conclusión, podemos decir que la normativa analizada proporciona instrumentos que permiten el control y prevención de la contaminación lumínica, pero está claro que aspectos como el horario de encendido de los alumbrados, cómo hacer frente al coste que supone la modificación de las instalaciones de alumbrado público, etc, no quedan cubiertos por la normativa analizada.

\section{La eficiencia energética}

La protección contra la contaminación lumínica debe ir orientada hacia la consecución del desarrollo sostenible ${ }^{98}$. No olvidemos que se trata de luchar contra el derroche de energía, no de limitar la seguridad en las actividades que necesitan la luz artificial para su realización. En la consecución de dicho desarrollo sostenible juega un papel esencial el ahorro y la eficiencia energética, lo que redundará en la lucha contra la contaminación lumínica.

El ahorro y la eficiencia energética, unido a las exigencias impuestas por el Protocolo de Kioto de reducir y controlar las emisiones de gases de efecto invernadero constituyen dos elementos clave en la política energética europea ${ }^{99}$,

\footnotetext{
98 Al respecto del concepto de desarrollo sostenible, vid, entre otros, LOZANO CUTANDA, B.: Derecho Ambiental Administrativo. Ed. Dykinson. Madrid. (2006, págs. 52 y ss.). PAREJO NAVAJAS, T.: «Los nuevos instrumentos jurídicos para el desarrollo sostenible del territorio de la Unión Europea». REALA n. ${ }^{\circ} 302$ (2006, págs. 211 y ss.).

La Sentencia de 20 de mayo de 2004 de la Audiencia Provincial de Barcelona, Sala de lo Civil (Pte. Jordi Seguí Puntas, fj.3) mantiene, refiriéndose a la escasa iluminación de una carretera, que la contaminación lumínica debe mantenerse en márgenes tolerables si se opta por un razonable modelo de desarrollo sostenible.
}

99 ARIÑo ORTIZ, Gaspar, ha puesto de manifiesto el incumplimiento generalizado en la Comunidad Europea de los compromisos asumidos en materia de ahorro energético y reducción de emisiones de gases de efecto invernadero, en su libro Energía en España y Desafía Europeo. Seguridad, concentración empresarial, competencia, regulación. Ed. Comares y Fundación de Estudios de Regulación. Granada (2006, págs. 2 y 3$)$.

Al respecto de la política energética comunitaria debe tenerse en cuenta el Libro Verde para la Eficiencia energética, de 22 de junio de 2005, el Plan de Acción (200-2006), el Plan de Acción para la Eficiencia Energética (2007-2012) y el Programa «energía inteligente-Europa (2007-2013)». 
a cuya consecución se puede contribuir aplicando los instrumentos de prevención y control de la contaminación lumínica ${ }^{100}$.

Uno de los objetivos, nada desdeñables, que pretende conseguir toda la normativa reguladora de la contaminación lumínica es la eficiencia energética. Así, se establece en la Ley de Calidad del Aire y Protección de la Atmósfera que prevé como uno de los objetivos a conseguir en la lucha contra la contaminación lumínica el «promover un uso eficiente del alumbrado exterior», ello sin menoscabo de la seguridad que el mismo está llamado a proporcionar ${ }^{101}$. En el mismo sentido se pronuncian las legislaciones autonómicas que se refieren a dicho tipo de contaminación ${ }^{102}$.

Si tenemos en cuenta que las actividades de producción de energía eléctrica se asocian principalmente a empresas contaminantes, que emiten dióxido de carbono a la atmósfera, nos encontramos con que la prevención y lucha contra la contaminación lumínica se convierte a su vez en una lucha contra la contaminación de la atmósfera.

Precisamente las actividades de generación de electricidad que emitan dióxido de carbono a la atmósfera se someten a la Ley que regula el Régimen de Comercio de Derechos de Emisión de Gases de Efecto Invernadero ${ }^{103}$, con la que se pretenden cumplir los compromisos asumidos por España con la ratificación del Protocolo de Kyoto de la Convención Marco sobre Cambio Climático de las Naciones Unidas, de 30 de mayo de $2003^{104}$.

La reducción de emisiones de gases de efecto invernadero como medida para paliar los efectos del llamado «Cambio Climático», puede acometerse, no sólo mediante ese comercio de derechos de emisión de este tipo de gases, sino mediante la aplicación generalizada de medidas contra la contaminación lumínica. Ello obviamente debe ir acompañado de otro tipo de medidas como la

\footnotetext{
100 Sobre la incidencia de la normativa ambiental en el sector energético, vid. ForTES MARTíN, A.: «La aplicación de los instrumentos normativos de tutela ambiental en el sector energético: retos e incertidumbres en las grandes instalaciones de combustión a partir del nuevo escenario ambiental resultante del régimen de prevención y control integrados de la contaminación» en el libro colectivo Derecho de la Energía. Ed. La Ley. (2006 págs. 710 y ss.).

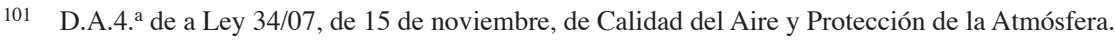

102 Art. 2.b) de la Ley 3/05, de 20 de abril, de Protección del Medio Nocturno de las Isles Balears; art. 2.a de la Ley Foral 10/05, de 9 de noviembre, de Ordenación del Alumbrado para la Protección del Medio Nocturno; art. 6. c) de la Ley 7/07, de 9 de julio, de Gestión Integrada de la Calidad Ambiental.

103 Ley 1/05, de 9 de marzo, que regula el Régimen del Comercio de Derechos de Emisión de Gases de Efecto Invernadero.

104 M. Teresa CARGalleIRA RIVERA: «El cambio climático. Análisis científico y jurídico de la problemática de la emisión de gases de efecto invernadero», en RDU y MA n. ${ }^{\circ} 156$ (1997, págs. 161 y ss.). J.M. ${ }^{\mathrm{a}}$ MARTín BERNAL: «Notas resumidas sobre Kioto», en RDU y MA n. ${ }^{\circ} .218$ (2005, págs. 167 y ss.) I. SANZ RUBIALES: «Una aproximación al nuevo mercado de derechos de emisión de gases de efecto invernadero», en REDA n. ${ }^{\circ} .125$ (2005, págs. 32 y ss.). I. GonZÁLEZ Ríos: «Instrumentos de mercado en la tutela ambiental. Una visión actualizada sobre su implantación». RAAP n. 64 (2006, págs. 190 y ss.).
} 
potenciación de la utilización de energías renovables menos contaminantes o medidas asociadas al transporte y a la movilidad.

A esta normativa hemos de unir la Estrategia de Ahorro y Eficiencia Energética en España 2004-2012 (E4), aprobada por el Consejo de Ministros el 28 de noviembre de 2003. Este documento establece como uno de los elementos básicos de la política energética española «compatibilizar el uso de la energía con una protección efectiva del medioambiente, de manera que se cumplan las exigencias de un desarrollo sostenible a largo plazo». La protección del medio ambiente se convierte en una de las razones de la adopción de la citada Estrategia, que se fija, entre otros, como objetivo la reducción de emisiones de contaminantes atmosféricos.

Entre las medidas que en dicha Estrategia se proponen para el ahorro y eficiencia energética destacan las centradas en el sector industrial y de transporte, y sólo colateralmente, en lo que se denominan como «usos diversos»(residencial, terciario y servicios públicos), se evalúa el potencial ahorro energético en la edificación, en la iluminación, en la potabilización del agua, etc. Se recoge así una estrategia de eficiencia energética para los edificios, que entre otros aspectos se refiere a la iluminación (introducción de lámparas de bajo consumo...) Es en el sector de los servicios públicos, constituido por el alumbrado público y semáforos y la depuración y bombeo de agua, donde se pueden incardinar los objetivos de la Estrategia en cuanto a prevención de la contaminación lumínica. Entre las medidas previstas figuran: la sustitución del alumbrado público por luminarias y lámparas más eficientes, junto con la instalación de sistemas automáticos de regulación del alumbrado.

Resulta curioso que la propia Estrategia de Ahorro y Eficiencia Energética considere que los principales impedimentos o barreras al ahorro y eficiencia energética sean, en primer lugar, institucionales, por el impulso de actividades de mejora del suministro y consumo de energía sin la correspondiente contrapartida de la mejora de la eficiencia energética o por carencia de normativas, o ausencia de campañas de información general.

La inversión en infraestructuras de eficiencia energética es generalmente rentable, como manifiesta el documento que comentamos.

En definitiva, la Estrategia de Ahorro Energético se vincula a la protección del medio ambiente centrándose en la reducción de emisiones a la atmósfera de gases de efecto invernadero como correlación a una disminución del consumo de energía o a un uso más eficiente. Pero sería conveniente la expresa previsión en este tipo de Estrategias de que las medidas coadyuven también a evitar la contaminación lumínica y, en consecuencia, a preservar la visión del cielo nocturno, la no intrusión de luz en viviendas, la protección de la salud y la protección de los hábitats naturales. 
Incidiendo en la misma materia, se ha aprobado la Estrategia Española de Cambio Climático y Energía Limpia horizonte 2007-2012-2020105 (EECCEL) y el Plan de Energías Renovables 2005-2010106. La citada Estrategia aborda diferentes medidas que contribuyen al desarrollo sostenible en el ámbito del cambio climático y energía limpia. Entre ellas se sitúan, por un lado, las destinadas a mitigar el cambio climático centrándose en la reducción de las emisiones de GEI, por otro lado, las que pretenden conseguir una reducción en los consumos energéticos sin afectar al desarrollo sostenible.

Con el objeto de llevar a cabo algunas de las medidas propuestas en dicha Estrategia se aprueban, por un lado, el Plan de Medidas Urgentes de la EECCEL, donde se identifican las iniciativas indicadas en la Estrategia, que siendo competencia del Gobierno de la Nación, pueden ponerse en marcha durante el año 2007, y por otro lado, el segundo Plan de Acción de Ahorro y Eficiencia Energética 2008-2012107.

Resultado de las previsiones contenidas en dichas Estrategias y Planes de acción para el ahorro y la eficiencia energética ha sido la reciente aprobación del Reglamento de Eficiencia Energética en Instalaciones de Alumbrado Exterior ${ }^{108}$, que específicamente se propone mejorar el ahorro y la eficiencia energética y limitar la contaminación luminosa.

Comunidades Autónomas como Murcia, Castilla-La Mancha o Andalucía han aprobado legislaciones específicas sobre energías renovables y eficiencia energética $^{109}$. Andalucía ha aprobado la Ley de Fomento de las energías renovables y del Ahorro y Eficiencia Energética ${ }^{110}$, que si bien no se refiere al efecto de la contaminación lumínica respecto de dicha eficiencia energética, sí contiene determinaciones directamente relacionadas con la misma. Así, se recoge la obligación de la ciudadanía y de los poderes públicos de usar la energía de forma racional, eficiente y procurando el máximo ahorro. Los poderes públicos están obligados a prever los instrumentos jurídicos necesarios para impulsar el ahorro y eficiencia energética, así como, a fomentar la sustitución de equipos e instalaciones obsoletos por otras de mejor rendimiento. Además, todas las Administraciones públicas

\footnotetext{
105 Aprobada por el Consejo Nacional del Clima de 25 de octubre de 2007 y Consejo de Ministros de 2 de noviembre de 2007.

106 Aprobado por Consejo de Ministros de 26 de agosto de 2005, constituye una revisión del Plan de Energías Renovables 2000-2010.

107 Plan de Acción 2008-2012 (E4). El primer Plan de Acción abarcó el periodo 2005-207, y se aprobó por el Consejo de Ministros de 8 de julio de 2005.

108 Real Decreto 1890-2008, de 14 de noviembre.

109 Ley 10/06, de 21 de diciembre, de Energías Renovables y Ahorro y Eficiencia Energética de la Región de Murcia; Ley 1/07, de 15 de febrero, de Fomento de las Energías Renovables e Incentivación del Ahorro y Eficiencia Energética en Castilla La Mancha y Ley 2/07, de 27 de marzo, de Fomento de las Energías Renovables y del Ahorro y Eficiencia Energética de Andalucía.

110 Ley 2/07, de 27 de marzo, de fomento de las energías renovables y del ahorro y eficiencia energética de Andalucía.
} 
de Andalucía están obligadas a implantar medidas de ahorro y eficiencia energética dentro del ámbito de sus propias instalaciones y actividades ${ }^{111}$.

La interrelación existente entre protección contra la contaminación lumínica y el ahorro y la eficiencia energética y el desarrollo sostenible obliga a la aprobación de una legislación básica sobre contaminación lumínica, ya reivindicada por la Doctrina, que contenga previsiones específicas sobre la regulación sectorial que incide en la materia. Se exige en esta materia una articulación entre la regulación del sector eléctrico, las regulaciones sobre eficiencia energética, el urbanismo y la ordenación del territorio, la normativa de Costas, Puertos y Carreteras, entre otras.

\section{CONCLUSIONES}

A pesar de las reivindicaciones doctrinales, seguimos asistiendo a la falta de una legislación estatal básica en materia de contaminación lumínica. Se ha desaprovechado la ocasión con la aprobación de la Ley de Calidad del Aire y Protección de la Atmósfera que, a pesar de definir dicho fenómeno contaminante, deja en manos de las Administraciones públicas competentes su prevención y reducción, estableciendo exclusivamente los objetivos a conseguir.

La aprobación del Reglamento de Eficiencia Energética en Instalaciones de Alumbrado Exterior ha venido a paliar en parte esa ausencia de regulación básica estatal en la materia. Pero en la medida en que el mismo se centra en las condiciones técnicas que deben reunir aquellos aspectos fundamentales de la contaminación lumínica que quedan fuera de su regulación.

Parece olvidar el legislador estatal que este tipo de contaminación excede en ocasiones el ámbito local e incluso regional (pensemos en la iluminación de las zonas costeras), y que no sólo la protección del medio ambiente, sino también, otros títulos competenciales como la energía, las instalaciones eléctricas, la iluminación de costas y señales marítimas, la seguridad pública o la investigación científica y técnica le habilitan para la regulación de la materia, respetando, por supuesto, las competencias autonómicas y locales.

La relevancia de los bienes jurídicos a proteger con los instrumentos de prevención y control de la contaminación lumínica avalan además, esa legislación básica. Pensemos en la necesidad de conseguir el ahorro y la eficiencia energética, en garantizar el derecho a una vivienda digna, libre de intrusiones lumínicas que perjudiquen el descanso nocturno, en la necesidad de preservar la visión del cielo nocturno para permitir la investigación científica y la protección del paisaje como garantía de la calidad de vida en las ciudades, etc. Esta

111 Así se deduce de los arts. 5, 20, 23 y 24 de la Ley 2/07, de 27 de marzo, de fomento de las energías renovables y del ahorro y eficiencia energética de Andalucía. 
normativa estatal básica al menos debe establecer: los límites máximos admisibles de contaminación lumínica según la zonificación del territorio, que pueden realizar las CCAA y los municipios; la exigencia de que la contratación administrativa se vincule al cumplimiento de la normativa sobre contaminación lumínica; la obligación de adaptación de los alumbrados exteriores contaminantes; las exigencias técnicas a cumplir por los aparatos destinados a la iluminación de exteriores o los límites máximos y mínimos en cuanto a las sanciones a imponer en esta materia. Además, la técnica prevista en la llamada Ley del Cielo de que el alumbrado de edificios públicos, monumentos, etc, queden apagados a partir de las 12 de la noche resulta sumamente conveniente. Dicha técnica puede contribuir a aplicar y llevar a cabo la normativa sobre ruidos en los municipios. Está claro que la falta de iluminación de edificios, jardines, etc, y la reducción de la iluminación vial, podría desincentivar la práctica de actividades lúdicas en la calle. Ello no obstante, debería ir acompañado de excepciones al apagón generalizado del alumbrado en cuanto a actividades de recreo a partir de las 12, permitiendo, en lugares estrictamente tasados y fijados por los Ayuntamientos, la existencia de iluminación durante fines de semana, que permita la práctica de esta «cultura urbana» que realizan actualmente los jóvenes.

La ordenación y regulación de la prevención de la contaminación lumínica resulta un instrumento idóneo para luchar contra la misma y para conseguir la eficiencia energética.

Si a ello unimos el hecho de que cuando controlamos la contaminación lumínica, consiguiendo dicha eficiencia energética, estamos contribuyendo a reducir la emisión de gases de efecto invernadero, podemos concluir en la absoluta necesidad de realizar una regulación mínima común para todo el territorio nacional sobre prevención y lucha contra la susodicha contaminación.

En definitiva, en la protección contra la contaminación lumínica se echa en falta, en primer lugar, una regulación básica estatal completa en la materia y un desarrollo legislativo por parte de todas las CCAA, con expresa previsión de las competencias municipales al respecto; $y$ en segundo lugar, una absoluta falta de coordinación entre las normativas sectoriales relacionadas con la iluminación de determinados bienes o con la eficiencia energética. Carece de sentido que la regulación estatal y autonómica existente sobre eficiencia energética, a pesar de contener medidas de eficiencia energética íntimamente relacionadas con la protección contra la contaminación lumínica ni siquiera se refieran a la misma. 
